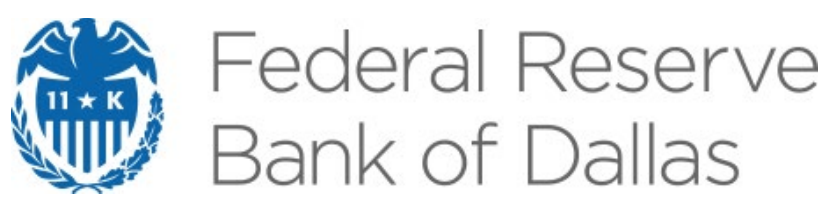

\title{
A Quantitative Evaluation of the Housing Provident Fund Program in China
}

Xiaoqing Zhou

Working Paper 2008

March 2020

Research Department

https://doi.org/10.24149/wp2008

Working papers from the Federal Reserve Bank of Dallas are preliminary drafts circulated for professional comment. The views in this paper are those of the authors and do not necessarily reflect the views of the Federal Reserve Bank of Dallas or the Federal Reserve System. Any errors or omissions are the responsibility of the authors. 


\title{
A Quantitative Evaluation of the Housing Provident Fund Program in China*
}

\author{
Xiaoqing Zhou ${ }^{\dagger}$
}

February 28, 2020

\begin{abstract}
The Housing Provident Fund (HPF) is the largest public housing program in China. It was created in 1999 to enhance homeownership. This program involves a mandatory saving scheme based on labor income. Past deposits are refunded when the worker purchases a house or retires. Moreover, the program provides mortgages at subsidized rates to facilitate these home purchases. I calibrate a heterogeneous-agent life-cycle model to quantify the effects of these policies. My analysis shows that a housing program with these features is expected to raise the rate of homeownership by 8.7 percentage points and to increase the average home size by $20 \%$. I discuss the economic mechanisms by which these outcomes are achieved and which features of the HPF program are most effective. I also consider several extensions of the model such as requiring employers to contribute to the program and allowing renters to withdraw funds from the HPF.
\end{abstract}

Keywords: Public policy, Housing Provident Fund, Policy evaluation, China, Life-cycle model, Homeownership.

JEL Codes: E2, E6, H3, R2, R3.

\footnotetext{
* thank Jason Allen, Joshua Hausman, Lutz Kilian and Dmitriy Stolyarov for helpful comments and discussions. The views in this paper are solely the responsibility of the author and should not be interpreted as reflecting the views of the Federal Reserve Bank of Dallas or the Federal Reserve System. This research did not receive any specific grant from funding agencies in the public, commercial, or not-for-profit sectors.

${ }^{\dagger}$ Corresponding author: Xiaoqing Zhou, The Federal Reserve Bank of Dallas, 2200 N. Pearl St., Dallas, TX 75201, USA. Email:xqzhou3@gmail.com.
} 


\section{Introduction}

Governments around the world take measures to promote homeownership. These actions are driven by the belief that housing, for most households, is both an important investment asset and a consumption good, and that homeownership promotes social and economic stability (see, e.g., DiPasquale and Glaeser (1999)). The U.S. government, for example, has fostered homeownership by encouraging subprime lending and by expanding secondary mortgage markets (see, e.g., Mian and Sufi (2009) and Gabriel and Rosenthal (2010)). Many Asian governments, in contrast, have adopted centralized mandatory saving plans to assist households with their housing needs. The Housing Provident Fund (HPF) in China is one such an example. Table 1 provides examples of similar programs in other countries.

The HPF was first enacted in 1999 and has been applied to an increasing number of regions in China since then. ${ }^{1}$ The policies stipulated by the HPF apply to all urban workers, regardless of the type of the firm they work for (state-owned, collective or private). There are two key features of this program. First, it is a mandatory saving scheme that requires households to save for their future home purchases. Specifically, the government requires each worker to deposit a mandatory fraction of her salary to the program until the worker purchases her first house, at which point the government refunds the worker's past deposits. If the worker never purchases a house during her working life, the program returns all past deposits to the worker at the time of retirement. Second, the program provides mortgages at discounted rates to participants. The HPF is the largest public housing program in China, both in terms of the number of workers enrolled and the funds deposited and distributed. According to the annual report published by the Ministry of Housing and Urban-Rural Development in China, in 2015, 124 million workers have enrolled in the HPF ( $40 \%$ of urban employment), 1.5 trillion Yuan ( $2 \%$ of GDP) were deposited in the program, and 1.1 trillion Yuan were lent out for home purchases and building. It is expected that this program will eventually be extended to all urban workers.

There has been much interest in the question of how effective the HPF program has been at stimulating homeownership (see, e.g., Logan et al. (1999), Li (2000), Fu et al. (2000), Huang and Clark (2002), Buttimer et al. (2004), Meng et al. (2005), Yeung and Howes (2006), Xu

\footnotetext{
${ }^{1}$ For further details on the HPF and a review of the history of related Chinese housing policies see Xu (2016).
} 
(2016) and Tang and Coulson (2017)). Evaluating the success of this program empirically is not straightforward. There are several challenges. For example, at the individual level, workers may choose when to participate in the program, which depends on their unobserved characteristics. Cross-sectional regressions that compare those who participate to those who do not, therefore, suffer from selection bias. Alternatively, one may exploit variation across regions in the timing of the implementation of this program. It is likely, however, that regions implementing the program late may have already anticipated the change before the implementation. Thus, this approach could underestimate the true effect of the program. Finally, at the national level, these policies have been implemented for only a short period of time, limiting the use of time-series methods for estimating the program impact.

Given these empirical challenges, a natural alternative approach to quantifying the effects of this program is to use a structural model. For this purpose, I develop a heterogeneous-agent life-cycle model and conduct a series of policy experiments using the calibrated model. The use of quantitative theory also helps to understand the mechanisms through which these polices can affect the housing market. I focus on two outcome variables: the rate of homeownership and the average home size. The baseline model without government intervention captures the consumption and savings behavior of Chinese households over their life cycle. Households can choose both the timing and the size of their home purchases. Within the same generation, households are heterogeneous in that each home purchase is associated with a random transaction cost. As a result, homeownership and average home size vary over the life cycle and across households. I calibrate the model based on household survey data from the Chinese Household Income Project Series (CHIPS). The model produces a rate of homeownership increasing with age and a roughly flat path of the average home size over the life cycle.

I then incorporate the key features of the HPF program into this model. First, the mandatory saving scheme is captured by a parameter that represents the fraction of income to be deposited into the program. Second, the mortgage subsidies are captured by the spread between the market rate and the rate offered by the program. I set these parameters to the values currently implemented in the HPF program and compare the life-cycle paths of homeownership and average home size with the corresponding paths in the baseline model. The objective is to capture the steady-state effects 
of the HPF policies on housing demand when all urban workers are covered by this program.

My analysis shows that a housing program with these features is expected to increase the rate of homeownership by 8.7 percentage points, corresponding to a $14 \%$ increase relative to the baseline model. This increase is mainly due to the fact that some households, who would otherwise have bought a house later in life, push forward their purchases, and that some households, who would otherwise never have bought a house, choose to become homeowners. In addition, the average home size increases by $20 \%$ relative to the baseline model. This effect is driven by the increase in the size of new homes across all age groups.

My analysis also helps to understand which features of the HPF program are most effective. Two additional policy experiments shed light on this question. First, I consider a housing program that requires mandatory savings but that does not offer mortgages at discounted rates. Second, I consider a program that offers discounted mortgages but that does not require mandatory savings. The first experiment shows that the mandatory saving scheme, as currently implemented by the HPF, has almost no impact on home purchases and consumption behavior. This is because, for most households, the mandatory savings required by the program are below their optimal private savings in the absence of the policy. When the program is implemented, households keep the sum of their mandatory and private savings equal to their optimal private savings in the absence of the policy. Since other conditions such as income, transaction costs and prices are unchanged, these households make exactly the same home purchase and consumption decisions. In contrast, the second experiment shows that the subsidized mortgages offered by the program create a wealth effect by lowering the borrowing costs. This effect pushes forward the timing of home purchases and allows households to purchase larger homes. My analysis suggests that a program featuring only discounted mortgage rates is able to replicate all the effects of the current HPF program.

There are several ways of extending the model to capture additional features of the HPF program. For example, employers are required by the government to contribute to workers' HPF savings. I examine how workers change their home purchase decisions depending on how much employers contribute. Moreover, an increasing number of cities has allowed non-homeowners to withdraw their HPF deposits to cover their rental expenditures. I study how this policy affects households' and especially renters' decisions. Finally, I incorporate the supply side of the housing 
market based on the recent empirical estimates of housing supply elasticity in China to gauge the impact of the HPF program on house prices and aggregate housing demand. Since housing supply at the national level is fairly elastic, the estimated price effect is small (2.7-4.7\%) compared to the effect on quantities (13.7-15.8\%).

The remainder of the paper is organized as follows. Section 2 describes the baseline model and discusses how to incorporate the key features of the HPF program into the baseline model. Section 3 outlines the model calibration. Section 4 quantifies the effect of mandatory savings and discounted mortgage rates based on a series of policy experiments. Section 5 studies the role of employers' contributions. Section 6 further extends the model to incorporate renters' withdrawal and the supply side of the housing market. Section 7 concludes.

\section{Model}

The baseline model is intended to capture households' decisions about non-housing consumption, savings, the timing of a home purchase, and the home size purchased. This partial equilibrium life-cycle framework is designed to capture household decisions at both the extensive and intensive margins and to generate rich heterogeneity across households in their wealth accumulations and spending patterns (see, e.g., Ortalo-Magne and Rady (2006), Yang (2009), Berger et al. (2018), Wong (2016), Kaplan et al. (2019), Guren et al. (2018) and Zhou (2019)). ${ }^{2}$

Due to the transaction cost and the down-payment requirement associated with a home purchase, households have to first accumulate wealth before they can make a home purchase. When they decide to purchase a home, they also need to choose the size of the home. The model has two important features. First, I assume that a household purchases a house, if at all, only once in its life. This assumption appears realistic for the Chinese residential housing market. According to Huang and Yi (2011), in 2002, only 6.6\% of urban households in China owned two or more homes. Second, a house purchase is associated with a randomly drawn transaction cost. This feature creates heterogeneity in the timing of home purchases, in the size of the homes purchased and in non-housing consumption across households within the same generation. The advantage of

\footnotetext{
${ }^{2}$ I abstract from other sectors of the economy because the focus of the paper is on assessing how effective the HPF program is at reaching its stated objective. This approach avoids the difficult task of developing a fully specified model of the Chinese economy.
} 
modeling random transaction costs compared to modeling idiosyncratic income shocks is that it can capture a range of unobserved time-varying or location-specific determinants of home purchases in China, such as regulations, policies, taxes and fees.

\subsection{Baseline Model}

The model is built on a discrete-time version of Leahy and Zeira (2005). I extend the model to include random transaction costs, housing collateral constraints and the rental market. The economy is populated with overlapping generations of households whose income and wealth differ across the life cycle. In each period, a mass of households is born and lives for $J$ periods. In the first $J_{y}$ periods of life, households work and earn labor income. In the remaining $J-J_{y}$ periods, households retire and receive retirement income.

Households derive utility from consuming the non-housing good and housing services. Utility is additive in the two goods. Let $u(c)$ denote the flow utility from consuming the non-housing good, where $c$ is non-housing consumption (henceforth referred to as consumption). Let $v(h)$ denote the flow utility from consuming the housing services generated by an owner-occupied home of size $h$. $u(\cdot)$ and $v(\cdot)$ satisfy the usual assumptions for a well-defined utility function. Households who do not own a home can choose a rental house of size $s$ at a unit rental cost of $R$ per period. Unlike homeowners, renters can adjust their housing size without paying a transaction cost. On the other hand, the rental cost is higher than the user cost of owner-occupied housing, which drives renters to become homeowners.

Households start their lives without owning a house. In each period, they make decisions about consumption, savings, the size of rental housing if they are not a homeowner, whether to become a homeowner if not already and the size of the home if they decide to buy. At the end of the life cycle, households leave their wealth as a bequest, consisting of liquid savings and home equity (the value of the house net of debt). In the baseline model, I assume that a house never depreciates. This assumption is relaxed in Section 4.6, where I discuss how the depreciation rate is relevant for household decisions and its implications for the effects of the HPF program. 
The expected lifetime utility is given by

$$
\mathbb{E}_{0}\left\{\sum_{j=0}^{J-1} \beta^{j}\left[u\left(c_{j}\right)+v\left(h_{j}\right)\right]+\beta^{J} \Phi\left(w_{J}, h_{J}\right)\right\},
$$

where the second term inside the expectation operator represents the discounted utility from leaving a bequest, specified by the bequest function $\Phi$, the functional form of which is discussed in Section 3. $w_{J}$ denotes the wealth at the end of the household's life.

The household problem has a recursive form. The value at the end of the household's life is given by the bequest function

$$
\Phi((1+r) a+p h, h)
$$

where $a$ denotes savings, $p$ denotes the house price and $r$ denotes the interest rate. For $j=$ $0, \ldots, J-1$, the value function depends on whether the household owns a house at the beginning of the period. If the household owns a house of size $h$ at the beginning of period $j$, the value function is given by

$$
\begin{gathered}
V_{j}^{O}(a, h)=\max _{c, a^{\prime}} u(c)+v(h)+\beta V_{j+1}^{O}\left(a^{\prime}, h\right) \\
\text { s.t. } \quad c+a^{\prime}=y+(1+r) a \\
\quad-a^{\prime} \leq \gamma p h .
\end{gathered}
$$

The first constraint is the budget constraint, where $y$ denotes age-specific income. The second constraint is the housing collateral constraint. It implies that a homeowner cannot borrow more than a fraction $\gamma$ of its home value. Thus, $1-\gamma$ is the down-payment rate.

If the household does not own a house at the beginning of the period, the value function, $V_{j}^{N O}$ is the maximum of the value of purchasing a home, $V_{j}^{P}$, and not purchasing, $V_{j}^{N P}$, i.e.,

$$
V_{j}^{N O}(a, f)=\max \left\{V_{j}^{P}(a, f), V_{j}^{N P}(a)\right\}
$$

The value of purchasing a home is

$$
\begin{gathered}
V_{j}^{P}(a, f)=\max _{c, a^{\prime}, h^{\prime}, s} u(c)+v(s)+\beta V_{j+1}^{O}\left(a^{\prime}, h^{\prime}\right) \\
\text { s.t. } \quad c+R s+a^{\prime}+p h^{\prime}=y+(1+r) a-f \\
-a^{\prime} \leq \gamma p h^{\prime},
\end{gathered}
$$

where $f$ is an i.i.d. transaction cost drawn from a continuous distribution $F$. The value of not 
purchasing a home is

$$
\begin{gathered}
V_{j}^{N P}(a)=\max _{c, a^{\prime}, s} u(c)+v(s)+\beta \mathbb{E}\left[V_{j+1}^{N O}\left(a^{\prime}, f^{\prime}\right)\right] \\
\text { s.t. } \quad c+R s+a^{\prime}=y+(1+r) a \\
a^{\prime} \geq 0,
\end{gathered}
$$

where $\mathbb{E}\left[V_{j+1}^{N O}\left(a^{\prime}, f^{\prime}\right)\right]=\int_{-\infty}^{\infty} V_{j+1}^{N O}\left(a^{\prime}, f^{\prime}\right) d F\left(f^{\prime}\right)$. The second constraint is the liquidity constraint, which requires liquid savings to be non-negative. The presence of the housing collateral constraint and the liquidity constraint jointly implies that any positive borrowing amount must be collateralized by a house. The policy function is characterized by a cut-off rule. For each age $j$ and a wealth level $a$, there exists a cut-off transaction cost value, $f_{j}^{*}(a)$, such that the household purchases a house if $f \leq f_{j}^{*}(a)$ and it does not purchase a house if $f>f_{j}^{*}(a)$.

\subsection{Modeling Mandatory Savings}

One important feature of the HPF program is a mandatory saving requirement for workers who are not homeowners. Specifically, the government requires each worker to deposit a mandatory fraction, $\theta$, of her salary to the HPF until the worker purchases her first house, at which point the government refunds the worker all past deposits. ${ }^{3}$ The mandatory saving policy, therefore, affects the budget constraint of non-purchasers by subtracting part of their income. The value function of these households, $V_{j}^{N P}, j=0, \ldots, J y-1$, is

$$
\begin{gathered}
V_{j}^{N P}(a)=\max _{c, a^{\prime}, s} u(c)+v(s)+\beta \mathbb{E}\left[V_{j+1}^{N O}\left(a^{\prime}, f^{\prime}\right)\right] \\
\text { s.t. } \quad c+R s+a^{\prime}=(1-\theta) y+(1+r) a \\
a^{\prime} \geq 0 .
\end{gathered}
$$

If a worker decides to purchase a house, the HPF returns the past deposits made by the worker together with the accumulated interests. The value function of purchasing a house at age $j=$

\footnotetext{
${ }^{3}$ After a worker purchases her first house, the HPF still collects a fraction of the worker's salary. Unlike in the case of non-homeowners, the program does not retain the deposits of homeowners, and it quickly returns the collected funds to these workers usually within a quarter. Therefore, the disposable income of homeowners is not affected. In the baseline evaluation, I assume that existing homeowners are not affected by the HPF program. This assumption is relaxed in Section 5.2 where I allow households to be affected by the HPF program even after their home purchases.
} 
$1, \ldots, J y$ is

$$
\begin{gathered}
\quad V_{j}^{P}(a, f)=\max _{c, a^{\prime}, h^{\prime}, s} u(c)+v(s)+\beta V_{j+1}^{O}\left(a^{\prime}, h^{\prime}\right) \\
\text { s.t. } \quad c+R s+a^{\prime}+p h^{\prime}=y+(1+r) a-f+\theta \sum_{k=0}^{j-1} y_{k}(1+r)^{j-k} \\
-a^{\prime} \leq \gamma p h^{\prime} .
\end{gathered}
$$

If the worker never purchases a house during her working life, the HPF returns all past deposits to the worker at the time of retirement. This implies that the budget constraint of households who have not been a homeowner at the retirement age includes an extra income term, $\theta \sum_{k=0}^{J_{y}-1} y_{k}(1+$ $r)^{J_{y}-k}$. Since the mandatory saving requirement does not apply to retired households, the value functions over retirement are the same as in the baseline model.

Current HPF policies require firms to contribute to the program by matching their workers' deposits. The combined deposits can be withdrawn by workers for home purchases during the working life or at the retirement age. Suppose employers are required by the program to match a fraction, $x$, of their workers' HPF deposits, where $0 \leq x \leq 1$. The combined deposits of a worker in period $t$ is $(1+x) \theta y_{t}$. This implies that a worker who purchases a house at age $j$ can

withdraw $(1+x) \theta \sum_{k=0}^{j-1} y_{k}(1+r)^{j-k}$ from the program. These employers' contributions are likely to affect households' decisions on home purchases. In Section 5, I analyze in detail how employers' contributions alter the effectiveness of the HPF program depending on the required matching rate, the eligibility of households and the withdrawn policy.

\subsection{Modeling Discounted Mortgage Rate}

In an effort to make housing affordable, the HPF also provides mortgages at discounted rates. These rates are set by the central bank, People's Bank of China (PBOC). According to the PBOC, the historical spread between the long-term market mortgage rate and the HPF's lending rate is about 2 percentage points. To model the discounted mortgage rate, I separate households' financial assets into two components: liquid savings that earn the market rate of interest and mortgage debt that is repaid at the rate specified by the HPF. Note that having two financial assets in the model introduces an additional state variable, which greatly increases the computational burden. 
The value function at the end of a household's life is

$$
\Phi\left((1+r) a+p h-\left(1+r^{b}\right) b, h\right)
$$

where $a$ denotes liquid savings, $r$ denotes the market interest rate, $b$ denotes the amount of mortgage debt and $r^{b}$ denotes the mortgage rate offered by the HPF.

The value function of a homeowner becomes

$$
\begin{gathered}
V_{j}^{O}(a, h, b)=\max _{c, a^{\prime}} \quad u(c)+v(h)+\beta V_{j+1}^{O}\left(a^{\prime}, h, b^{\prime}\right) \\
\text { s.t. } \quad c+a^{\prime}=y+(1+r) a-M \\
a^{\prime} \geq 0 \\
b^{\prime}=\left(1+r^{b}\right) b-M
\end{gathered}
$$

where $M$ is the periodic mortgage payment. $b^{\prime}$ is the mortgage outstanding balance at the beginning of the next period. Liquid savings have to be non-negative. I consider a repayment schedule that requires HPF borrowers to pay back at least the interest every period. This approach makes the predictions based on this two-asset model comparable to the one-asset model in Sections 2.1 and 2.2 .

If a household does not own a house at the beginning of the period, the value of not owning, $V_{j}^{N O}$, is the maximum of the value of purchasing a house, $V_{j}^{P}$, and of not purchasing $V_{j}^{N P}$. Note that $V_{j}^{N P}$ is the same as in the baseline model because a lower mortgage rate will not affect households who choose not to buy a home. $V_{j}^{P}$, however, becomes

$$
\begin{gathered}
V_{j}^{P}(a, f)=\max _{c, a^{\prime}, h^{\prime}, b^{\prime}, s} u(c)+v(s)+\beta V_{j+1}^{O}\left(a^{\prime}, h^{\prime}, b^{\prime}\right) \\
\text { s.t. } \quad c+R s+a^{\prime}+p h^{\prime}=y+(1+r) a-f+b^{\prime} \\
0 \leq b^{\prime} \leq \gamma p h^{\prime} \\
a^{\prime} \geq 0 .
\end{gathered}
$$

Given this analysis, it is straightforward to combine Sections 2.2 and 2.3 to model the two program features simultaneously. The model is solved numerically by using backward induction through a two-step procedure. In the first step, I discretize the state space and then solve the value 
functions over fixed grids of the states. In the second step, I obtain the policy functions by solving the optimization problem over finer grids given the value functions obtained in the first step. The numerical procedure is described in detail in Appendix A.

\section{Calibration}

To quantify the impact of the HPF program, the model parameters are calibrated. A summary of the parameter values can be found in Table 2. Age is indexed by $j=0, \ldots, J-1$. The model frequency is five years. Households start their lives at age 21, work for 40 years, and then live for another 20 years in retirement, so $J=12$ and $J y=8$. Households do not have initial liquid savings, mortgage debt or owner-occupied housing, i.e., $a_{0}=b_{0}=h_{0}=0$.

The discount factor is set to $\beta=0.93$. The flow utility from consumption is $u(c)=\ln c$ and that from housing services is $v(h)=\xi \ln h$, where $\xi$ denotes the utility weight on housing services. I set $\xi=0.25$, so that the expenditures on housing account for $20 \%$ of total consumer expenditures. This is consistent with the expenditure share of housing and household goods in total consumer expenditures for urban households in China between 1998 and 2002, according to the Statistical Yearbook published by the National Bureau of Statistics of China.

The bequest function is given by

$$
\Phi(w, h)=\eta[u(w)+v(h)]
$$

where $w$ denotes wealth at the end of the life cycle. $u(\cdot)$ and $v(\cdot)$ were specified earlier. $\eta$ is the bequest parameter. Since a direct measurement of the bequest motive is hard to obtain from the data, I conducted a sensitivity analysis for different values of $\eta$. I found that the effects of the HPF program are not sensitive to alternative values. Therefore, I set $\eta=1$.

I use household survey data from the CHIPS in 2002 to calibrate household income by age group. ${ }^{4}$ The survey collects income data between 1998 and 2002. I construct the life-cycle income path as follows. First, I obtain a measure of income for each household by averaging the income of the household across these years. Second, I regress the log of this income measure on the first

\footnotetext{
${ }^{4}$ The CHIPS surveys are intended to measure the distribution of personal income in both rural and urban areas of China. These survey data were collected in 1988, 1995 and 2002. Individual respondents reported their demographic characteristics, income, employment, and expenditures. I obtained the 2002 CHIPS data from the ICPSR at the University of Michigan.
} 
and second polynomials of the age of the household head. The coefficients from the regression can be used to construct a smooth income path over the life cycle. Third, I take the average of the estimated income within each age group, and normalize the income of age group 21-25 to 1. Figure 1 shows the age distribution of income used to calibrate the model.

The down-payment rate, $1-\gamma$, is set to $22 \%$. This is consistent with the regulation of residential housing markets implemented by the government during the 2000s, which required a minimum down-payment rate for the first home of $20-25 \%$. The i.i.d. transaction costs are assumed to be uniformly distributed with a lower bound of zero (i.e., $f_{0}=0$ ). The upper bound is set to 0.6 to match the overall rate of homeownership in the data (i.e., $f_{1}=0.6$ ). The house price is normalized to $p=1$. The rental cost $R$ is calibrated as follows. In the CHIPS data, homeowners report their own home value. They also give an estimate of how much they expect to charge if they rent their home out. The ratio of these two variables implies a rent-to-price ratio, $R / p$, of 0.1 on average. ${ }^{5}$ Given the calibrated house price, $R=0.1$.

The mandatory fraction of income to be deposited into the program is set to $\theta=0.12$, consistent with the average workers' contribution rate across cities in China between 1999 and 2015. ${ }^{6}$ The market interest rate is set to $r=0.05$. In most policy experiments, I assume that the HPF program involves an interest rate spread of 2 percentage points, i.e., $r^{b}=0.03$.

\section{Policy Experiments}

In this section, I evaluate the impact of the HPF program on the rate of homeownership, the average size of owner-occupied homes and the expected life-time utility in steady state. First, I use the baseline model to characterize household decisions on home purchases, consumption and savings before the HPF program is introduced. I simulate the life-cycle choices of a large number of households, and use them to construct life-cycle paths averaged across households. ${ }^{7}$ I then calibrate a model that incorporates the key features of the HPF program and show that the program meets

\footnotetext{
${ }^{5}$ Note that this rent-to price-ratio is higher than the user cost of owner-occupied housing, $\frac{r+\delta}{\beta(1+r)}$, where $\delta$ is the housing depreciation rate, which is set to zero in the baseline calibration. Using the calibrated values of $r$ and $\beta$, this user cost is about 0.05. This difference drives renters to become homeowners in the model.

${ }^{6}$ The required fraction of income deposited into the program has been varying across cities and years. Between 1999 and 2015, this fraction fell to 5-20\%, with $12 \%$ being the most commonly used value.

${ }^{7}$ For each cohort, I simulate 10,000 households. All results are robust to increasing the number of simulated households.
} 
the government's objective of enhancing homeownership. The HPF also raises the average home size and consumers' expected utility. Since the program has two distinct features, each of which may affect households differently, I also investigate the impact of these two features separately. The results are summarized in Table 3. I conclude that the mandatory saving feature, as currently implemented, has almost no impact on households' home purchase decisions. Therefore, the effects of the HPF program are mainly driven by the feature of discounted mortgage rates. Finally, my analysis contributes to the ongoing discussion about the HPF reform by providing simulations for alternative policy scenarios.

\subsection{Pre-Policy Patterns}

The baseline model in Section 2.1 captures some of the key features of the Chinese residential housing market. For example, in the CHIPS data in 2002, the rate of homeownership is $61.5 \%$. In the calibrated model, it is $60.9 \%$. Moreover, the age profile of homeownership and the fraction of new home buyers in the calibrated model are consistent with the household survey data.

Figure 2 shows the life-cycle profile of seven key variables in the baseline model after averaging across all households within each age group. These variables include the rate of homeownership, the fraction of new home buyers, the size of all owner-occupied homes, of new homes and of rental houses, consumption and wealth. The upper-left panel captures a monotonically increasing pattern of homeownership over the life cycle. The difference in the homeownership rate between one age group and the previous age group represents the fraction of new home buyers, as reflected in the middle-left panel. The youngest households, aged 21 to 25 , choose not to buy a home because they have not saved enough for the down payment and the transaction cost. At age 26 to 30, about $8 \%$ of households buy a house and become homeowners. From age 31 to 40, the fraction of new home buyers increases more strongly, which explains the fast growing homeownership rate. By age 40, $43 \%$ of households are homeowners. After age 40, there are still households who become new homeowners, but at a decreasing rate. At the end of the life cycle, only about $4.4 \%$ of households are not homeowners.

The upper-right panel shows the average size of all homes within each age group. I set the home size for age 21-25 to zero because no one owns a home in this age group. Over the life cycle, the 
average size of all homes is gradually increasing but not varying much. However, examining the average size of new homes in the middle-right panel reveals that the size of new homes is increasing with age more rapidly. This is because households who have not become homeowners continuously accumulate liquid savings as they age and hence can afford larger houses when they choose to become homeowners.

The size of rental homes over the life cycle is smaller than for owner-occupied homes, for two reasons. First, renters have to accumulate savings for future home purchases. Second, renting a house is more expensive than owning a house because the rent is higher than the user cost of owner-occupied housing. In Section 4.6, I consider alternative rental market conditions and their implications for the HPF program. In particular, I examine the effect of the HPF program for different values of the rent-to-price ratio $(R / p)$ and the housing depreciation rate $(\delta)$.

The lower-left panel shows a hump-shaped path of consumption over the life cycle. Before age 50 , consumption is increasing due to the fact that households are constrained by their borrowing capacity. After age 50, consumption is decreasing because households are impatient. Wealth is fast growing before age 40, as households accumulate savings for home purchases; it flattens out after age 40 as the increase in homeownership slows down. The reason why wealth (unlike consumption) does not exhibit a hump shape is that households do not downsize their homes and that they have to maintain at least the amount of the down payment in their wealth portfolio.

\subsection{The Impact of the HPF Program}

Figure 3 shows the life-cycle profile of homeownership, the fraction of new home buyers, the size of owner-occupied homes and of new homes in the baseline model (solid lines) and in the model with the two HPF features (dotted lines). Under the HPF program, homeownership increases in all age groups beyond age 25 . The overall homeownership increases by 8.7 percentage points, which is equivalent to a $14 \%$ increase relative to the pre-policy scenario. At the end of the life cycle, only $1.2 \%$ of households are not homeowners, compared to a $4.4 \%$ in the baseline scenario.

These facts imply that the HPF program pushes forward some households' decisions on home purchases, and it also drives some households to become homeowners who otherwise would not have purchased homes. This can be clearly seen from the change in the fraction of new home buyers. 
Under the program, the fraction of new home buyers substantially increases between age 26 and 45. By age $45,72 \%$ of households have already become homeowners, compared to a $57 \%$ in the baseline scenario. Later in life, the fraction of new home buyers is smaller relative to the pre-policy scenario because of the push-forward effect of the program.

The HPF program also increases the average home size by $20 \%$. A decomposition by age group in the upper-right panel of Figure 3 shows that such an increase is uniform across all age groups. This comes from the fact that the program enables households in all age groups to choose larger homes when they make purchasing decisions (Figure 3, lower-right panel).

Since the program features two distinct policies, mandatory savings and discounted mortgage rates, each may affect homeownership and home size differently. To understand the economic mechanism underlying each program feature and to quantify the extent to which each feature achieves the goal of the policymaker, I conduct two additional policy experiments. First, I consider a housing program that requires mandatory savings but that does not offer mortgages at a discounted rate. Second, I consider a program that offers mortgages at lower rates but that does not require mandatory savings.

\subsection{The Effect of the Mandatory Saving Policy in Isolation}

In this section, I consider a mandatory saving program that requires participants to deposit $12 \%$ of their income every period until they purchase a home or retire, whichever is earlier. The program then returns participants their previous mandatory savings with interest. It turns out that this program has almost no effect on households' home purchase and consumption decisions. For most households, the homeownership rate and the average home size are the same as in the pre-policy scenario (Figure B1, upper panel). The intuition is that if the mandatory savings are below the optimal private savings in the absence of the policy, households reduce their private savings under the program to the extent that the sum of their private savings and mandatory savings is equal to the optimal private savings in the absence of the policy. Since other conditions such as income, transaction costs and prices are unchanged, households make exactly the same decisions as in the pre-policy case.

Figure 4 illustrates this intuition by plotting the total savings for non-homeowners and 
homeowners in each age group before and after the mandatory saving scheme is implemented. For non-homeowners, their savings determine their home purchases and consumption. Under the current policy parameter, $\theta=0.12$, households younger than age 50 would keep their total savings (the sum of private and mandatory savings) unchanged relative to the pre-policy level. For non-homeowners of age 50-60, the mandatory savings required by the program exceed the optimal level planned by these households, driving their private savings down to zero and distorting their consumption and home purchase decisions. The small change in the overall homeownership rate and home size is caused by these households. For homeowners, their total savings determine their consumption. Since their total savings consist of liquid savings and home equity, which are unaffected by the mandatory saving scheme, their consumption is unchanged.

The key to understanding the effect of a program featuring mandatory savings alone is whether these mandatory savings exceed the optimal private savings in the absence of the policy. Figure 5 illustrates several cases based on different values of $\theta$. When $\theta \leq 0.1$, households' savings decisions are not distorted. Thus, the program has no effect relative to the pre-policy scenario. When $\theta>0.1$, required savings are above the optimal level, forcing households to sacrifice their consumption to fulfill the requirement. This leads to excess savings. Later in life, households have more wealth due to the transfers of income from their early life. As a result, the probability of buying a home increases because households are unwilling to be constrained by the saving requirements and the only way to opt out is to become homeowners. On the other hand, demand for larger houses increases, especially for middle-aged and old households. Therefore, the distortion of savings actually raises homeownership and home sizes. These effects, however, come at the cost of lower consumption early in life and lower expected lifetime utility. I discuss these effects in a more general setting in Section 4.5.

\subsection{The Effect of the Discounted Mortgage Rate in Isolation}

I now consider the effects of a program that offers home buyers a mortgage rate 2 percentage points lower than the market rate (as currently implemented by the HPF) but no mandatory savings. This program replicates all the effects under the HPF program as shown in Figure 3. This can also be seen in Table 3 and Figure B1. Both homeownership and home size increase in all age 
groups beyond age 25. Therefore, the effects of the current HPF program are mostly driven by this feature.

This policy affects households' decisions mainly through a wealth effect due to lower borrowing costs. This effect increases homeownership by driving some households to buy a home earlier and by allowing some households, who otherwise would not be able to do so, to become homeowners. This effect also makes larger homes affordable. Moreover, homeowners are able to consume more because of the higher wealth level and hence have higher expected lifetime utility. Figure 6 plots the total savings and consumption of existing homeowners before and after the program. It shows that discounted mortgage rates allow homeowners to accumulate more wealth over the life cycle and to consume more.

\subsection{Alternative Policy Scenarios}

In this subsection, I examine the change in homeownership, average home size, fraction of households who never own a house and expected lifetime utility for different values of the two policy parameters: the fraction of income to be deposited, $\theta$, and the spread between the market

interest rate and the mortgage rate offered by the program, $\Delta r \equiv r-r^{b}$. This analysis helps to understand the effect of alternative policy scenarios, which is relevant for the ongoing discussion about reforming the HPF framework to better achieve the objectives of policy makers.

The simulation results in Table 4 reveal three patterns. First, for a given value of $\theta$, the rate of homeownership, the average home size and the expected lifetime utility monotonically increase with the mortgage rate spread. The fraction of households who never become homeowners declines as the spread widens. This is explained by the wealth effect brought about by lower borrowing costs, as in Section 4.4. Second, for a given value of the mortgage rate discount, the effects on these four variables hardly vary when $\theta$ is small. This is consistent with the intuition in Section 4.3. In these cases, the mandatory savings are below the optimal private savings in the absence of the savings requirement. Therefore, households' decisions are not distorted and they behave as in the scenario where $\theta=0$.

Third, for a given value of the mortgage rate discount, large values of $\theta$ (e.g., $\theta \geq 0.2$ ) increase homeownership and average home size. The higher homeownership rate is explained by the fact 
that young and middle-aged households push forward their home purchases in order to not be constrained by the program on their consumption and savings. In other words, the program can no longer force consumers to sacrifice their consumption for making the required savings when they become homeowners. The larger home size is explained by the fact that households, especially middle-aged and old households, are able to afford larger houses when they decide to buy a house due to the excess deposits they made earlier in life. Although choosing a large $\theta$ raises homeownership and average home size, this comes at the cost of lower consumption for young households. Since households' savings decisions are distorted by the mandatory savings, their expected lifetime utility is also lower. The lower panel of Table 4 shows that expected utility is monotonically decreasing with $\theta$.

Based on my analysis, a program that stipulates a large discount on mortgage rates and a small deposit fraction will reach the policymakers' goal and enhance consumers' expected utility. This conclusion, however, has two caveats. First, my model does not incorporate the cost of providing discounted mortgage rates. Modeling the cost side of the HPF program requires calibrating a general equilibrium model that entails government financing and the determination of interest rates. I leave this task for future research. Second, in my model, all consumers are forward-looking and have rational expectations, so mandatory savings are either ineffective or create distortions that lower utility. However, there is reason to believe that some consumers may not be forward-looking or rational, or that they have self-control problems that prevent them from making optimal decisions. In this case, mandatory savings may help consumers to reach welfare-enhancing outcomes.

\subsection{Sensitivity Analysis}

In the previous policy experiments, I assumed that the housing depreciation rate, $\delta$, is zero, which is broadly consistent with the durability of residential houses. Moreover, the rent-to-price ratio, $R / p$, is fixed at $10 \%$. Changes in these parameter values affect the cost of renting relative to owing a house and can alter the effect of the HPF program on homeownership and home sizes. In this section, I study whether the effcts of the HPF program differ if alternative rental market conditions, captured by $\delta$ and $R / p$, are considered. The main conclusion is that, when rental housing is more attractive in the pre-policy scenario, so more households are renters and the rate 
of homeownership is low, the extent to which the program can stimulate home purchases increases.

The upper panel of Figure 7 shows the change in homeownership and home size under the HPF program relative to the pre-policy scenario as the rent-to-price ratio increases from $6 \%$ to $10 \%$ in both economies. When the rent-to-price ratio is low, more households choose to be renters in the pre-policy scenario, the rate of homeownership is low and the average home size (across all age groups) is small. In this case, the HPF program working through the wealth effect of discounted mortgage rates is more effective in raising homeownership. Since home buyers also tend to choose larger homes than renters, the average home size increases. As the rent-to-price ratio increases and more households choose to become homeowners in the pre-policy scenario, the extent to which the HPF program can stimulate house purchases becomes limited.

The lower panel of Figure 7 shows how the effectiveness the HPF program changes with the rate of housing depreciation. To maintain their home, homeowners have to spend $\delta p h$ every period. A higher $\delta$ raises the user cost of owner-occupied housing. As a result, owing a home is less attractive than renting and more households choose to become renters in the pre-policy scenario. As the HPF program is introduced, the wealth effect brought about by low-rate mortgages brings down the user cost of owning, stimulates home purchases and raises average home size.

\section{The Effect of Employers' Contributions}

In this section, I investigate how employers' contributions to the HPF program by matching a fraction of their workers' HPF deposits alter the effectiveness of the program. I start by evaluating the case where employers only match workers' deposits before they purchase a home. I then present the results for the case where employers match workers' deposits both before and after their home purchases. In the former case, households delay their home purchases to maximize the matched contributions from their employers. In the latter case, allowing employers to also match homeowners' deposits makes it unnecessary for households to delay their home purchases and hence brings the homeownership rate closer to the case without employers' contributions. In both cases, employers' contributions effectively raise households' disposable income, allowing them to consume more, to choose larger homes and to have higher expected lifetime utility. 


\subsection{Matching Non-Homeowners' Deposits Only}

The current HPF policies require all legally established firms to contribute to the program by matching their full-time employees' HPF deposits. The rule stipulates that the amount contributed by an employer should not exceed its workers' own deposits into the program. How much an employer contributes, however, may vary according to the employer's economic condition and local regulations. Recent changes in policy have increased the flexibility of firms in making HPF contributions. These policies also allow firms in financial difficulties to further reduce their obligatory contributions. ${ }^{8}$

To capture the difference in the contribution made by employers, I assume that employers on average have to match a fraction, $x$, of workers' deposits, where $0 \leq x \leq 1$. Therefore, the total deposits of a worker to the program in period $t$ is $(1+x) \theta y_{t}$. The case of $x=0$ corresponds to no employer contributions; the case of $x=1$ means that employers match their workers' deposits dollar for dollar. Both the worker's deposits and the employer's contributions are refunded to the worker with interest when the worker purchases a house or retires, whichever is earlier. I set the other policy parameters at the current HPF level of $\theta=0.12$ and $r-r^{b}=0.02$. As in the previous section, I assume that existing homeowners are not affected by the program. This assumption is relaxed in Section 5.2.

Figure 8 shows homeownership and average home size (compared to no employers' contributions) for each age group as employers match $20 \%, 40 \%$ and $60 \%$ of workers' deposits. When employers match part of their workers' deposits, the rate of homeownership is lower for young and middle-aged households than without such matching. By the end of the life cycle, however, homeownership rates in the two scenarios converge. This implies that employers' contributions delay households' home-purchasing decisions. This result is expected because workers treat employers' contributions as windfall income, which continues to accumulate if workers stay as renters and deposit their income for a longer time. Since in this version of the model no workers' deposits or employers' contributions can be made after a worker becomes a homeowner, workers delay their home purchases, accumulate

\footnotetext{
${ }^{8}$ These policy changes were designed to reduce firms' operating costs and to stimulate firms' performance. See, for example, the official announcements made by the Housing Provident Fund Management Center of the Central Government in May 2016 and April 2018: http://www.zzz.gov.cn/html/zcfg/jc/13771.html; http://www.gov.cn/xinwen/2018-05/14/content_5290855.htm.
} 
total HPF deposits and buy a larger house later in life. This effect is stronger as the matching rate increases. In addition, employers' contributions effectively raise household total wealth, allowing them to consume more and to have higher expected utility. In the limiting case of $x=1$, the average homeownership rate falls to $45.5 \%$ with the largest decline among young workers, while the average home size and consumer welfare increase by $13 \%$ and $48 \%$, respectively, relative to the case of no employers' contributions.

\subsection{Matching Both Non-Homeowners' and Homeowners' Deposits}

In the previous policy experiments, I assumed that homeowners do not make mandatory HPF deposits. This assumption is motivated by the HPF policy that mandatory deposits made by homeowners can be withdrawn within a short period of time. The budget constraints of these households, therefore, are not affected by the program. This equivalence, however, breaks down if employers match homeowners' deposits. I now extend the model in Section 5.1 by allowing employers to match the deposits by both non-homeowners and homeowners at a matching rate of $x$. With this extension, the disposable income of homeowners is effectively raised by $x \theta y_{t}$ every period until they retire.

Figure 9 shows the homeownership rate and average home size (compared to matching non-homeowners' deposits only) for each age group as employers match 20\%, $40 \%$ and $60 \%$ of workers' deposits. The main findings can be summarized in three points. First, the homeownership rate is higher than under the case where employers only match renters' deposits, because households find it unnecessary to delay their home purchases in order to maximize total mandatory savings.

Second, the average size of all homes is smaller in the current scenario. With employers matching deposits of all workers, young households are more likely to become homeowners, but they choose smaller houses than households in other age groups due to their lower savings. In contrast, when employers only match renters' deposits, households delay their purchases and choose larger homes when they decide to buy. It is the difference in the composition of the home size across age groups in the two models that leads to the difference in the average home size. In fact, comparing the size of new homes for each age group in the two models, it is always larger in the case where employers match both renters and homeowners' deposits. Third, employers matching homeowners' 
deposits effectively raises homeowners' disposable income, allowing them to consume more and to have higher expected utility than when only renters' deposits are matched. ${ }^{9}$

\section{Extensions}

In this section, I futher extend the model and the evaluation of the HPF program in two dimensions. First, motivated by a recent trend in many Chinese cities, I model the case in which renters are allowed to withdraw part of their HPF savings to pay for rent. Second, I estimate the housing demand curves before and after the HPF program is implemented and use the empirical estimates of housing supply elasticity to infer the effect of the HPF program on the aggregate house price and demand.

\subsection{Allowing Renters to Withdraw HPF Deposits}

Recently, many cities in China have allowed households to withdraw part of their HPF deposits to cover rental expenditures. This section examines the effects of the HPF program when this feature is incorporated. I first consider the model without employers' contributions. Then, I extend the model of Section 5.1 to study how employers' contributions alter households', and, in particular, renters' behavior. I show that, without employers' matching deposits, allowing renters to withdraw their HPF savings does not change the effects documented in Section 4.2., whereas requiring employers to contribute to the program and allowing renters to withdraw the combined HPF deposits enhance homeownership and raise average home size, as well as benefit renters by increasing their consumption and rental housing size.

Consider the model in Section 4.2 where employers do not contribute to the program. Let $\zeta$ denote the fraction of workers' HPF deposits that can be withdrawn, $0 \leq \zeta \leq 1$. The budget constraint of a renter becomes

$$
c+R s+a^{\prime}=(1-\theta) y+(1+r) a+\zeta \theta y=(1-\tilde{\theta}) y+(1+r) a,
$$

\footnotetext{
${ }^{9}$ One important caveat of the analysis involving employers' contributions in this paper is that I do not model firms' costs of offering these contributions. A higher cost of making these contributions will bring down the profit, which could lead to lower wage and employment. On the other hand, government subsidies or partial exemptions may relieve these concerns. I leave this aspects of the HPF program to future research.
} 
where $\tilde{\theta} \equiv(1-\zeta) \theta$. The budget constraint of a home buyer becomes

$$
c+R s+a^{\prime}+p h^{\prime}=y+(1+r) a+b^{\prime}-f+\tilde{\theta} \sum_{k=0}^{j-1} y_{k}(1+r)^{j-k} .
$$

Since the other equations of the household problem do not change, allowing renters to withdraw part of their HPF savings is equivalent to reducing their mandatory deposit rate from $\theta$ to $\tilde{\theta}$. As shown in Sections 4.3 and 4.5, a value of $\theta=0.12$ (as implemented in the current HPF program) is too small to have a distortionary effect on households' decisions, so an even smaller mandatory saving fraction $\tilde{\theta}$ would not change the effects documented in Section 4.2.

Now, consider the model in Section 5.1 in which employers match a fraction, $x$, of renters' deposits. In addition, renters are allowed to withdraw a fraction, $\zeta$, of their combined HPF deposits every period. The budget constraint of the renter becomes

$$
c+R s+a^{\prime}=(1-\theta) y+(1+r) a+\zeta(1+x) \theta y=y-[1-\zeta(1+x)] \theta y+(1+r) a,
$$

The budget constraint of a home buyer becomes

$$
c+R s+a^{\prime}+p h^{\prime}=y+(1+r) a+b^{\prime}-f+(1+x)(1-\zeta) \theta \sum_{k=0}^{j-1} y_{k}(1+r)^{j-k} .
$$

Since employers' contributions create windfall income for households, allowing renters to withdraw the combined HPF deposits effectively shifts part of future windfall income to their early lives. If both $x$ and $\zeta$ are large, i.e., $\zeta(1+x)>1$, renters receive transfers rather than making payments. It can be shown that allowing renters to withdraw the combined HPF deposits raises homeownership relative to the scenario without employers' contributions and relative to the scenario without renters' withdrawals.

More importantly, allowing renters to withdraw part of their total HPF deposits helps them to better smooth consumption, as well as to rent larger houses as intended by the government. Figure 10 illustrates this point by plotting the rental size when renters are allowed to withdraw their total HPF savings (compared to the scenario in Section 4.2). It shows that young households are able to rent larger houses when they can turn part of future savings to current use, and that the larger the combination of $x$ and $\zeta$ is, the larger the rental housing size they can afford. ${ }^{10}$

\footnotetext{
${ }^{10}$ Extending the model in Section 5.2 will further strengthen the effectiveness of the HPF program.
} 


\subsection{The Equilibrium Effect of the HPF Program}

So far, I have focused on the demand-side responses to the HPF program and its various extensions, holding the house price constant. This analysis implicitly assumes that the supply of housing is very elastic, and that the housing programs under my study shift aggregate housing demand without triggering a price adjustment. This assumption is not unreasonable, given that the empirical literature has shown that the national price elasticity of housing supply is fairly elastic with estimates ranging from 2.8 to 5.6. At the same time, the fact that estimates of the housing supply elasticity are finite implies that the house price will change to dampen the quantity responses, which may lower the effectiveness of the HPF program.

In this section, I provide estimates of the change in the housing demand and in the house price associated with the HPF programs. First, I use the model to simulate aggregate demand for housing at each price level before and after the HPF program is implemented. The demand curves are downward sloping, parallel and well captured by a linear functional form after transforming the variables to logs. Second, I estimate a linear regression model based on the data simulated in the first step to obtain the estimates for the slope parameter (i.e., the housing demand elasticity) and the constant terms of the two demand curves. Third, I construct the supply curve using the empirical estimates of housing supply elasticity by Wang et al. (2012) and the fact that the supply curve crosses the pre-policy demand curve at the baseline equilibrium. Finally, I solve the demand and supply equations to estimate the change in the house price due to the implementation of the HPF program.

The aggregate housing demand curves are shown in the left panel of Figure 11. For a given price level, demand for housing is higher under the HPF program. The right panel of Figure 11 shows the log price-quantity combinations and the fitted demand curves. According to my estimates, the elasticity of housing demand is -0.91 .

When using the lower bound of the housing supply elasticity in Wang et al. (2012), the increase in the house price and quantity associated with the HPF program is $4.7 \%$ and $13.7 \%$, respectively. When using the upper bound of the housing supply elasticity, the increase in the house price and quantity is $2.7 \%$ and $15.8 \%$. To conclude, my estimates show that the HPF program has much larger impact on the quantity purchased than on the price of housing given the elastic housing 
supply in China on average.

\section{Conclusion}

There has been much interest in the question of how the HPF has affected homeownership in China. This question is of interest not only to Chinese authorities but to policymakers more broadly because similar policies have been implemented in a wide range of countries. Addressing this question empirically is not straightforward because of selection bias, the anticipation effect and the short duration of this program to date. An alternative approach to evaluating the expected effects of this program is the use of quantitative theory. Existing theoretical studies of this question have relied on representative-agent models (see., e.g., Buttimer et al. (2004) and Tang and Coulson (2017)). Such models are not well-suited for studying heterogeneity across households and the distributional effects of these policies because in representative-agent models either everyone or no one buys a house.

The current paper develops a heterogeneous-agent life-cycle model that allows home purchases to depend on households' age and unobserved characteristics. This model allows me to quantify the increase in homeownership in response to this program. I show that the HPF program is expected to increase the rate of homeownership by 8.7 percentage points in steady state. It also increases the average size of homes and households' expected lifetime utility.

One advantage of addressing this question based on a quantitative model is a better understanding of the mechanisms by which these policies affect economic outcomes. I find that the mandatory saving feature, as currently implemented, has almost no impact on households' purchase decisions because the mandatory savings are below the optimal savings in the absence of the policy. In this situation, households keep the sum of their private and mandatory savings under the program equal to the optimal savings in the pre-policy scenario. Since other conditions such as income, transaction costs and prices are unchanged, households make exactly the same decisions as before.

Another key feature of the HPF program is the provision of subsidized mortgages at a rate below the market rate. This feature alone accounts for all of the estimated effects of the HPF program. However, households' ability to take advantage of these mortgage subsidies depends on 
unobserved characteristics. In the calibrated model, the fraction of participating households who are unable to buy a house by the end of their life is about $1.24 \%$.

I also examined alternative policy scenarios captured by different values of the policy parameters and considered various extensions of the program such as requiring employers to match workers' deposits and allowing renters to cash out part of their HPF savings. These changes may raise or lower the homeownership rate through additional channels, but they do raise welfare. Finally, using recent empirical estimates of the housing supply elasticity, I estimate that the HPF program is expected to raise the house price by only $2.7-4.7 \%$, while raising the quantity of housing by $13.7-15.8 \%$.

Although the model presented in this paper is more realistic than previous theoretical models of Chinese housing policies, the analysis in this paper is only a first step. I showed that the modeling device of random transaction costs for potential home buyers in conjunction with heterogeneity in wealth within the same cohort suffices to match some of the key features of the Chinese housing market. The model abstracts from heterogeneity in family size. This simplifying assumption is reasonable to the extent that the one-child policy has largely eliminated this concern and that current efforts to increase population growth thus far have had little effect. Finally, a more detailed analysis of the effects of Chinese housing policies would have to take into account the costs of matching workers' deposits from the firms' point of view, the costs of running these programs from the government's point of view, and the implications for monetary policy. Incorporating these features into the life-cycle framework is nontrivial, which I leave for future research.

\section{References}

Berger, D. W., V. Guerrieri, , G. Lorenzoni and J. Vavra, "House Prices and Consumer Spending," Review of Economic Studies 85(3) (2018), 1502-1542. https://doi.org/10.1093/restud/rdx060.

Buttimer, R., A. Y. Gu And T. T. YAng, "The Chinese Housing Provident Fund," International Real Estate Review 7 (2004), 1-30. https://www.um.edu.mo/fba/irer/papers/past/Vol7/vol7_page1_30.htm. 
DiPasquale, D. And E. Glaeser, "Incentives and social capital: Are homeowners better citizens?," Journal of Urban Economics 45 (1999), 354-384. https://doi.org/10.1006/juec.1998.2098.

Fu, Y., D. K. Tse And N. ZhaO, "Housing Choice Behavior of Urban Workers in China's Transition to a Housing Market," Journal of Urban Economics 47 (2000), 61-87. https://doi.org/10.1006/juec.1999.2133.

Gabriel, S. A. And S. S. Rosenthal, "Do the GSEs Expand the Supply of Mortgage Credit? New Evidence on Crowd Out in the Secondary Mortgage Market," Journal of Public Economics 94 (2010), 975-986. https://doi.org/10.1016/j.jpubeco.2010.06.014.

Guren, A. M., A. McKay, E. Nakamura and J. Steinsson, "Housing Wealth Effects: The Long View," NBER Working Paper No. 24729. https://doi.org/10.3386/w24729, 2018.

Huang, Y. And W. Clark, "Housing Tenure Choice in Transitional Urban China: A Multilevel Analysis," Urban Studies 39 (2002), 7-32. https://doi.org/10.1080/00420980220099041.

Huang, Y. And C. YI, "Second Home Ownership in Transitional Urban China," Housing Studies 26 (2011), 423-47. https://doi.org/10.1080/02673037.2011.542100.

Kaplan, G., K. Mitman and G. L. Violante, "The Housing Boom and Bust: Model Meets Evidence," forthcoming: Journal of Political Economy. https://doi.org/10.1086/708816, 2019.

Leahy, J. And J. Zeira, "The Timing of Purchases and Aggregate Fluctuations," Review of Economic Studies 72 (2005), 1127-1151. https://doi.org/10.1111/0034-6527.00364.

LI, S., "Housing Consumption in Urban China: A Comparative Study of Beijing and Guangzhou," Environment and Planning A 32 (2000), 1115-1134. https://doi.org/10.1086/a32145.

LOGAN, J., Y. BIAN AND F. BIAN, "Housing Inequality in Urban China in the 1990s," International Journal of Urban and Regional Research 23 (1999), 3-25. https://doi.org/10.1111/1469-2427.00176.

Meng, X., R. Gregory And Y. WAng, "Poverty, Inequality and Growth in 
Urban China, 1996-2000," Journal of Comparative Economics 33 (2005), 710-729. https://doi.org/10.1016/j/jce.2005.08.006.

Mian, A. And A. Sufi, "The Consequences of Mortgage Credit Expansion: Evidence from the U.S. Mortgage Default Crisis," Quarterly Journal of Economics 124 (2009), 1419-1496. https://doi.org/10.1162/qjec.2009.124.4.1449.

Ortalo-Magne, F. And S. Rady, "Housing Market Dynamics: On the Contribution of Income Shocks and Credit Constraints," Review of Economic Studies 73 (2006), 459-485. https://doi.org/10.1111/j.1467-937x.2006.383_1.x.

TAng, M. And N. Coulson, "The Impact of China's Housing Provident Fund on Homeownership, Housing Consumption and Housing Investment," Regional Science and Urban Economics 63 (2017), 25-37. https://doi.org/10.1016/j.regsciurbeco.2016.11.002.

Wang, S., S. H. Chan And B. Xu, "The Estimation and Determinants of the Price Elasticity of Housing Supply: Evidence from China," Journal of Real Estate Research 34 (2012), 311-344. https://aresjournals.org/doi/pdf/10.5555/rees.34.3.7h305651800m7q65.

Wong, A., "Population Aging and the Transmission of Monetary Policy to Consumption," Northwestern University Working Paper, 2016.

Xu, Y., "Mandatory Savings, Credit Access and Homeownership: The Case of the Housing Provident Fund," Urban Studies 54 (2016), 3446-3463. https://doi.org/10.1177/0042098016676158.

YAng, F., "Consumption over the Life Cycle: How Different Is Housing?," Review of Economic Dynamics 12 (2009), 423-443. https://doi.org/10.1016/j.red.2008.06.002.

Yeung, S. And R. Howes, "The Role of the Housing Provident Fund in Financing Affordable Housing Development China," Habitat International 30 (2006), 343-356. https://doi.org/10.1016/j.habitatint.2004.02.007.

Zhou, X., "Home Equity Borrowing and the Boom-Bust Cycle in Consumption and Residential Investment," Working Paper. https://doi.org/10.2139/ssrn.2853059, 2019. 
Figure 1: Household income by age, China 1998-2002

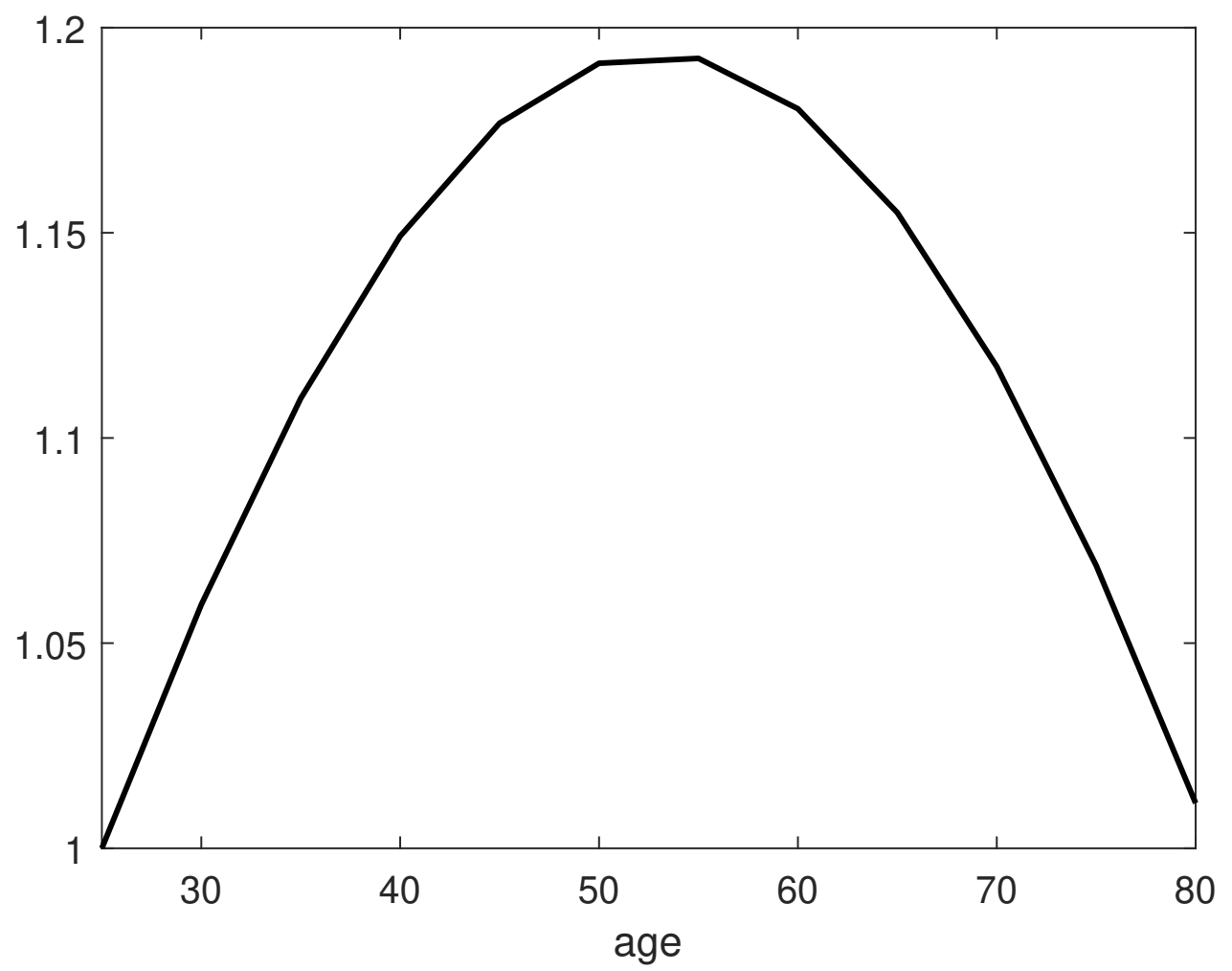

Note: This life-cycle profile of income is estimated based on survey data from the Chinese Households Income Project (CHIPS) 2002, and is used for calibrating the model. Income of age group 21-25 is normalized to 1. 
Figure 2: The baseline (pre-policy) patterns
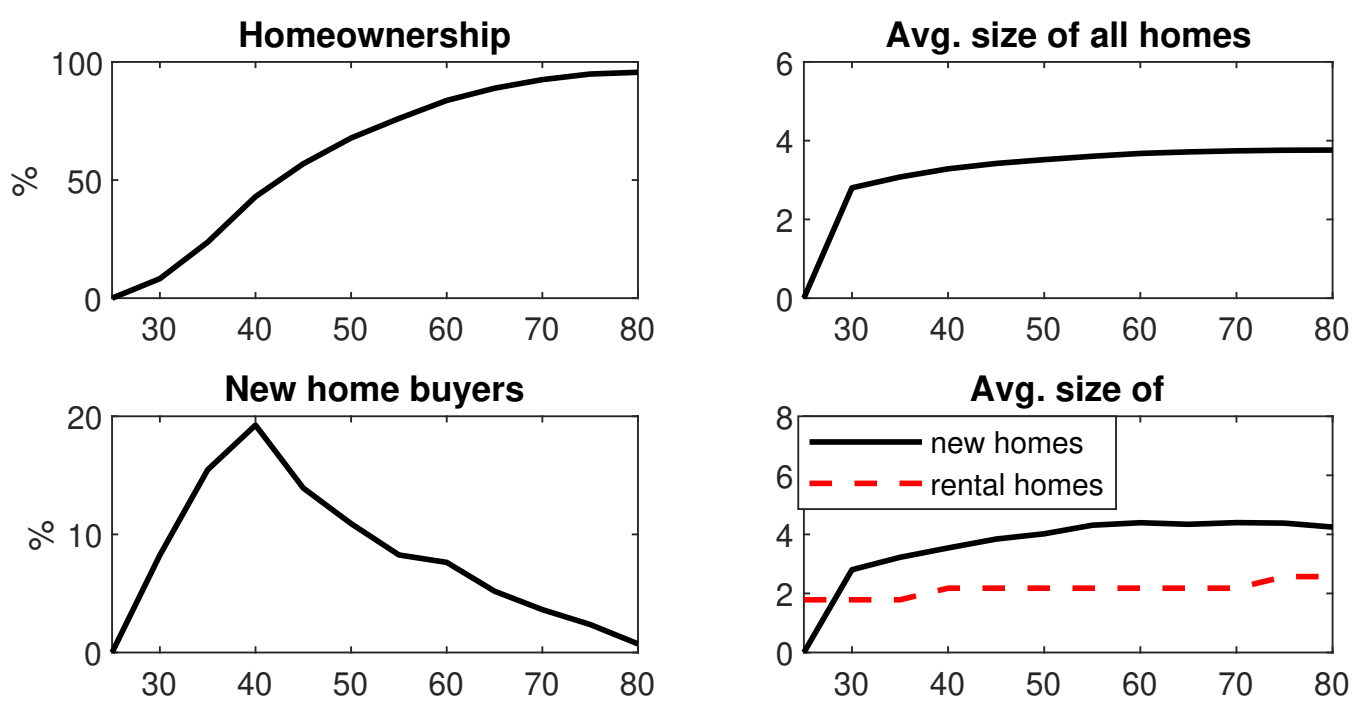

Avg. size of
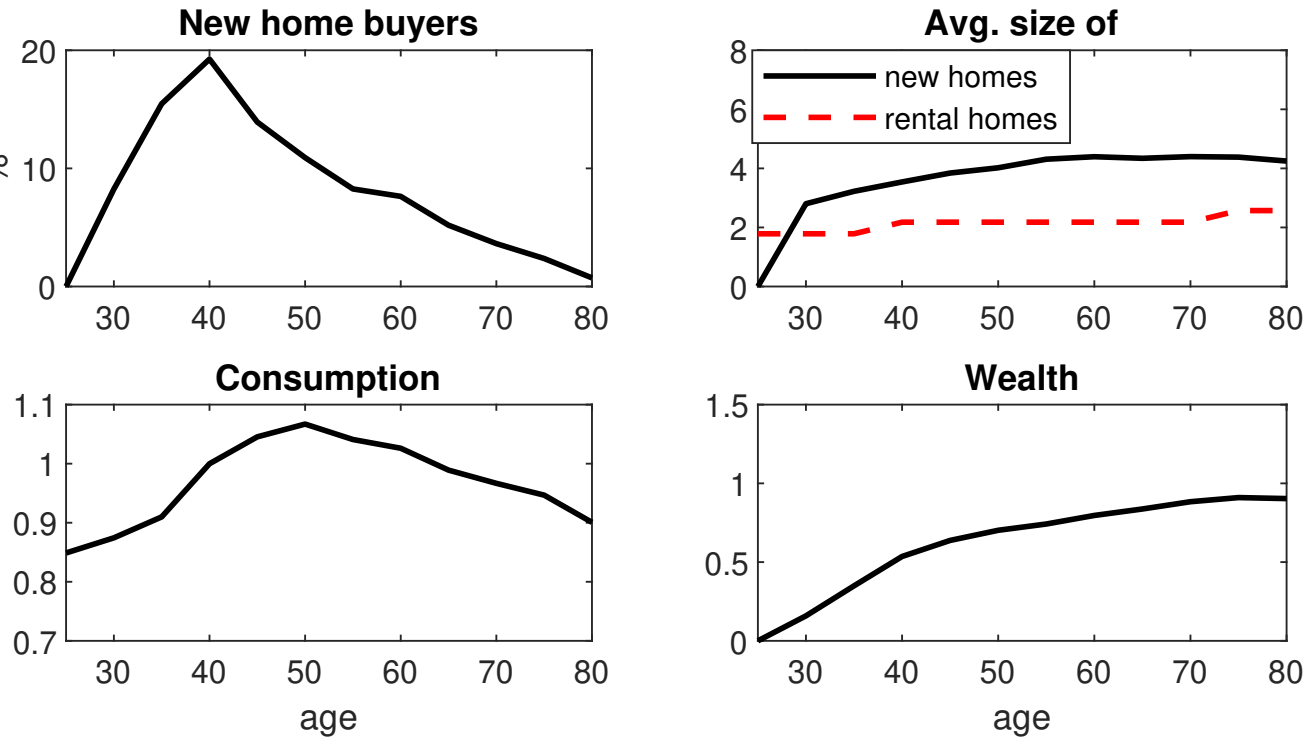

Notes: Simulations based on the pre-policy scenario in Section 2.1 by generating the life-cycle choices of a large number of households. "Homeownership" is the fraction of homeowners in each age group. "New home buyers" is the fraction of new home buyers in each age group. "Avg. size of all homes" is the average size of homes across all homeowners in each age group. "Avg. size of new homes" is the average size of homes bought by new homeowners in each age group. Home size measures are expressed in terms of the numeraire consumption good. "Consumption" refers to non-housing consumption. "Wealth" is the sum of net liquid savings and home equity. 
Figure 3: The impact of the HPF program
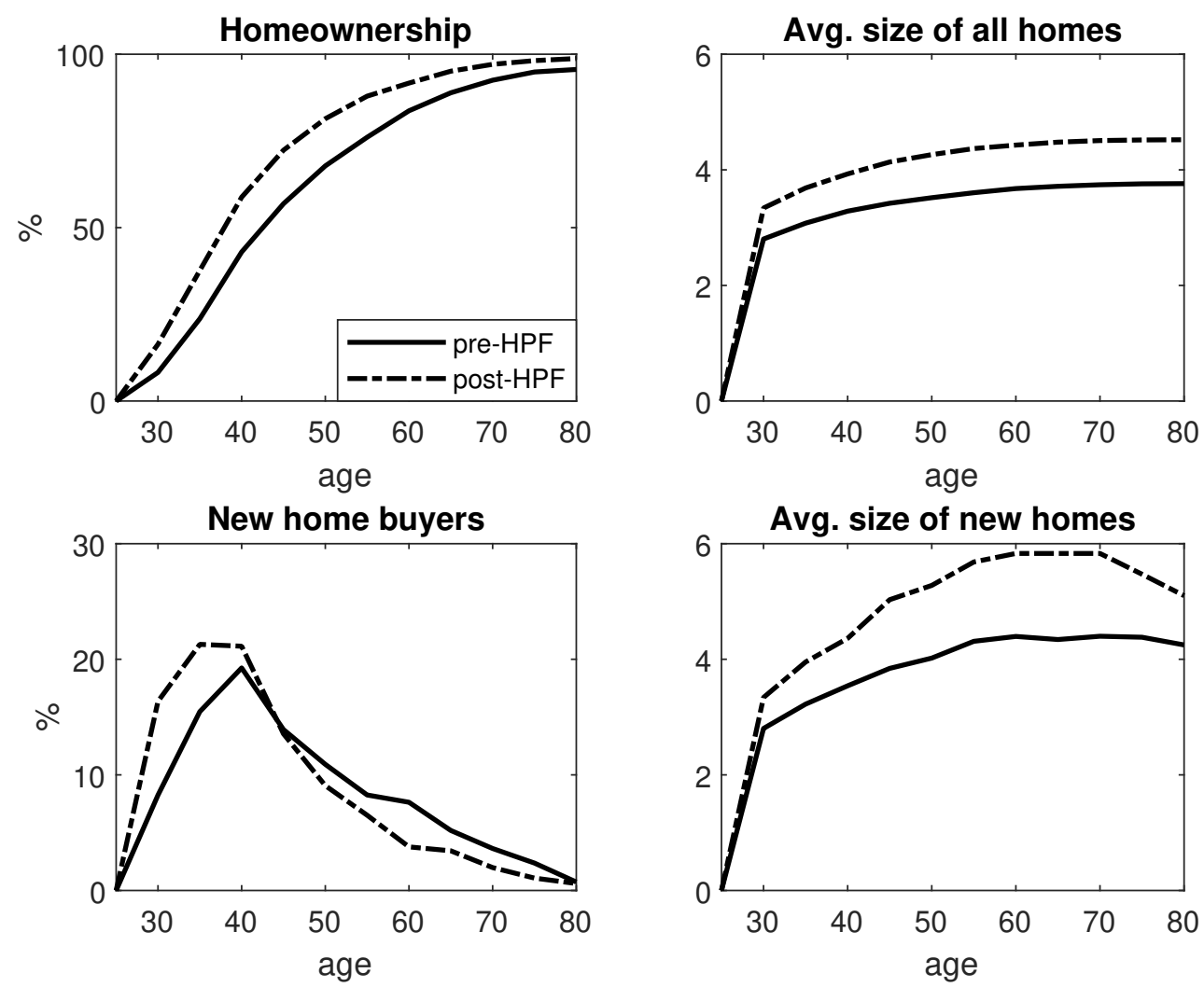

Notes: Simulations based on the baseline model in Section 2.1 and the model with both HPF features, $\theta=0.12, r-r^{b}=0.02$. 
Figure 4: The effect of mandatory savings on household total savings
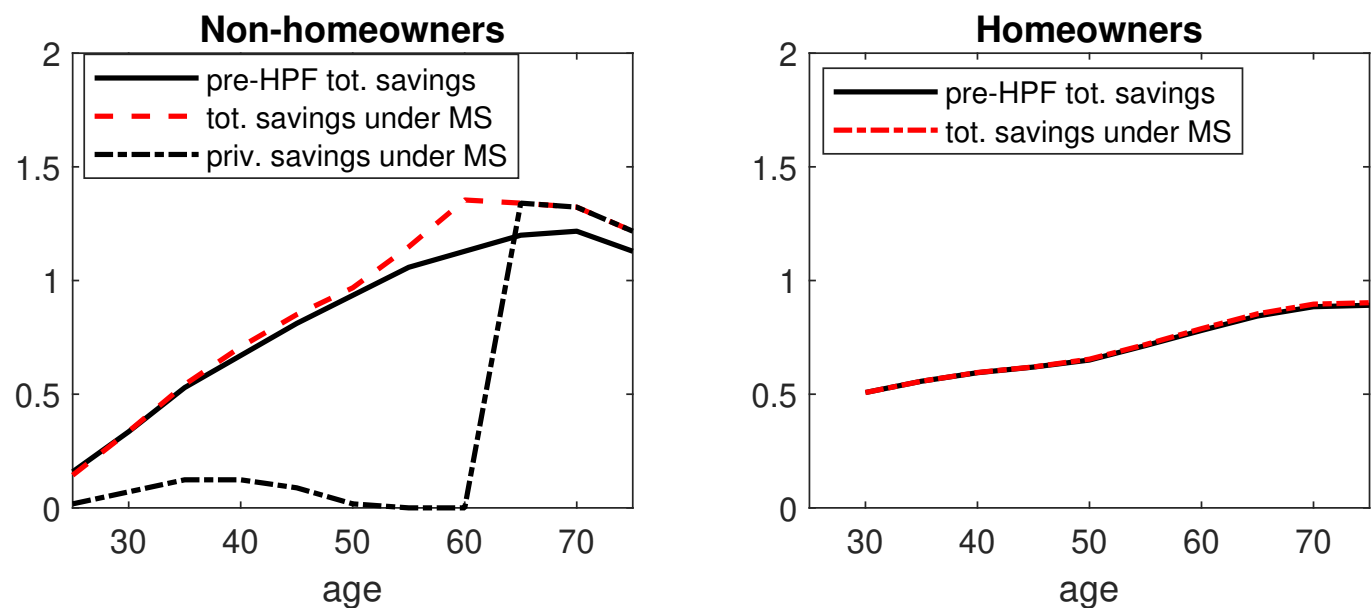

Notes: "MS" denotes "Mandatory Savings". Simulations are based on the model in Section 2.1 and the model with the mandatory saving feature only $\left(\theta=0.12, r=r^{b}\right)$. Total savings under MS is the sum of private savings and mandatory deposits.

Figure 5: Distortion of non-homeowners' savings caused by mandatory savings
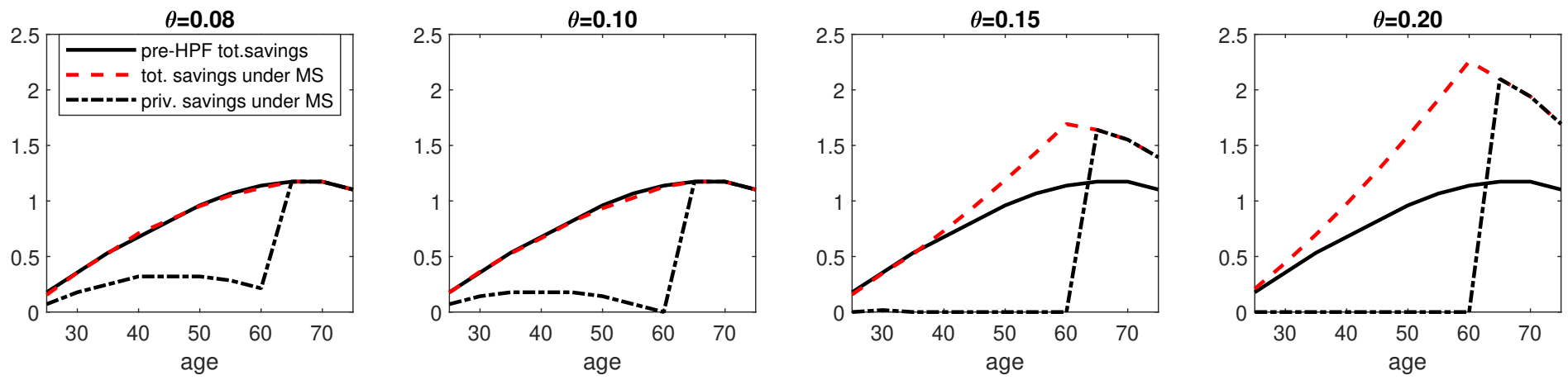

Notes: Simulations are based on the model in Section 2.1 and various mandatory saving only programs captured by $\theta$. 
Figure 6: The effect of discounted mortgage rate
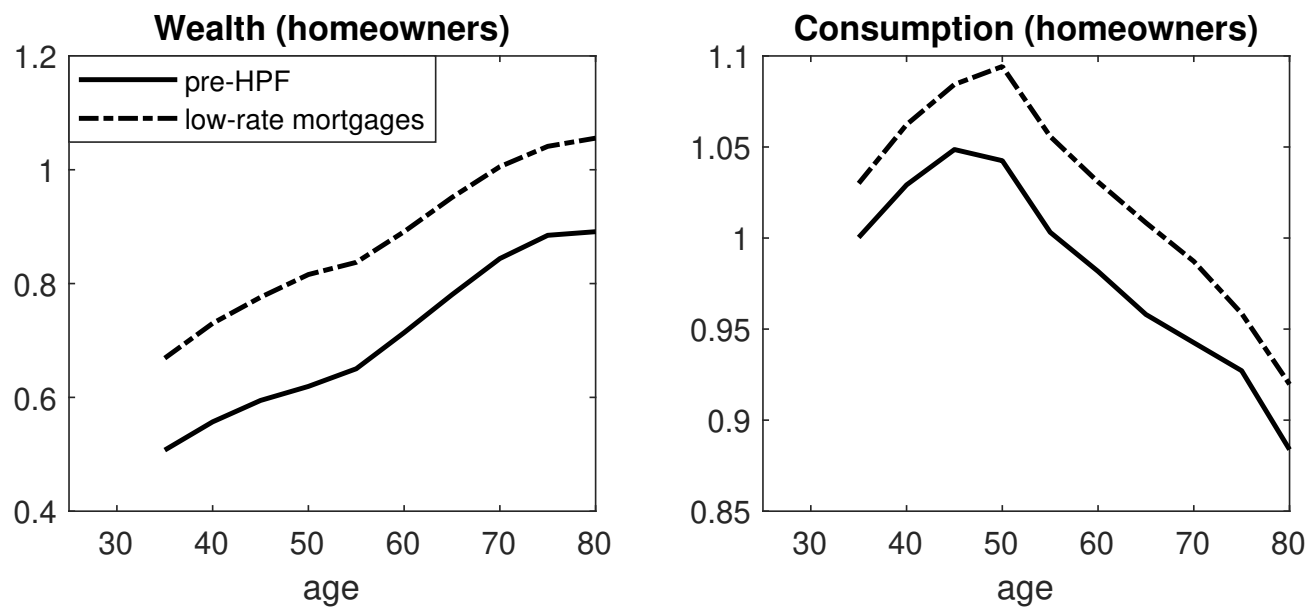

Notes: Simulations are based on the model in Section 2.1 and the discounted mortgage rate only program $\left(\theta=0, r-r^{b}=0.02\right)$. This figure illustrates wealth and consumption of existing homeowners (excluding new home buyers).

Figure 7: Sensitivity analysis
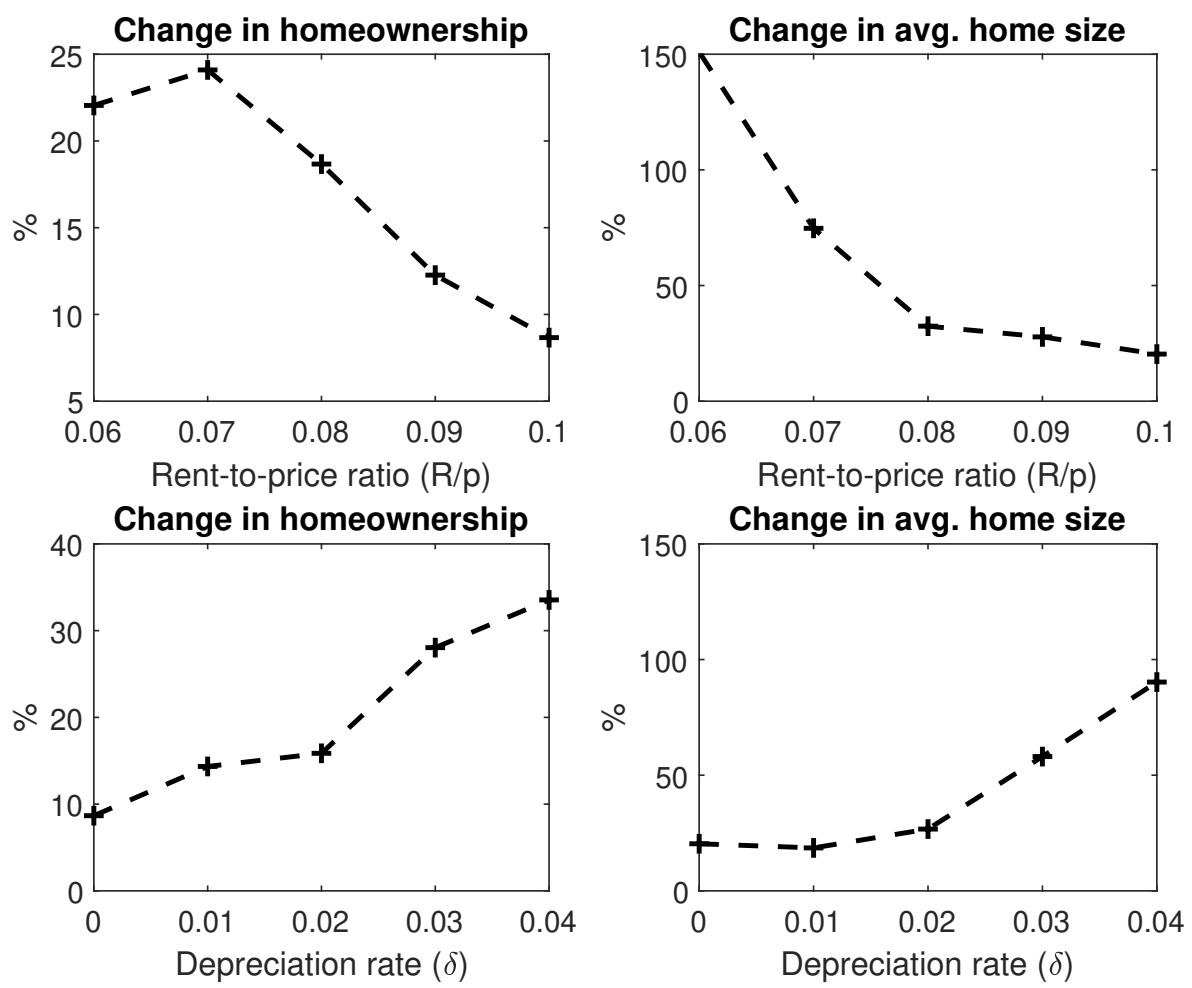

Notes: This figure illustrates the change in the homeownership rate (percentage points) and the change in the average home size (percent) relative to the pre-HPF scenario for different values of the rent-to-price ratio $(R / p)$ and the depreciation rate $(\delta)$. The policy parameters are fixed at their current HPF levels, i.e., $\theta=0.12$ and $r-r^{b}=0.02$. The pre-HPF scenario is recomputed for each value of $R / p$ and $\delta$. 
Figure 8: The effect of employers' contributions (matching non-homeowners' deposits)
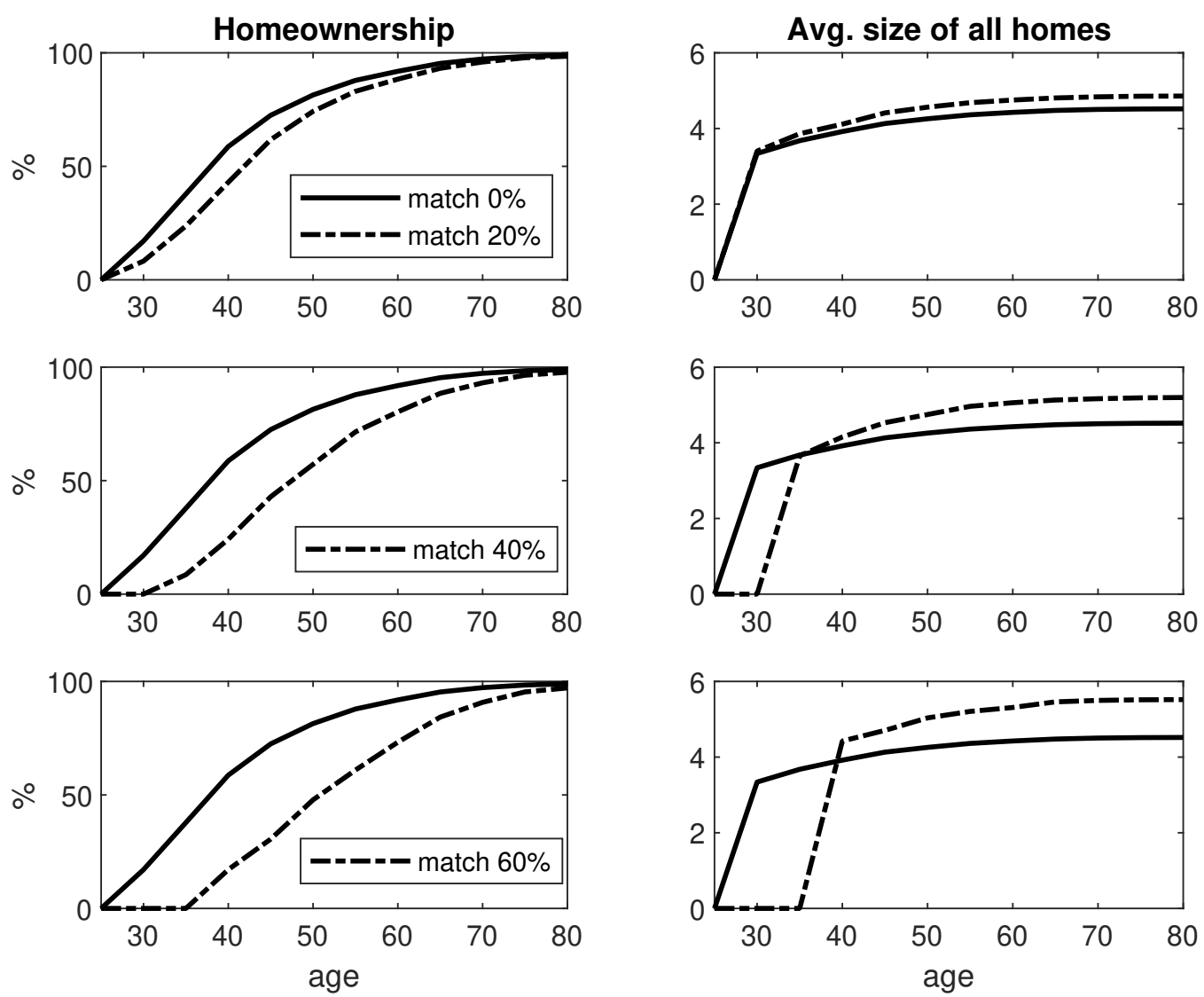

Notes: This figure illustrates homeownership and average home size under the program without employers' contributions and the program with employers matching the deposits of non-homeowners. 
Figure 9: The effect of employers' contributions (matching both non-homeowners' and homeowners' deposits)
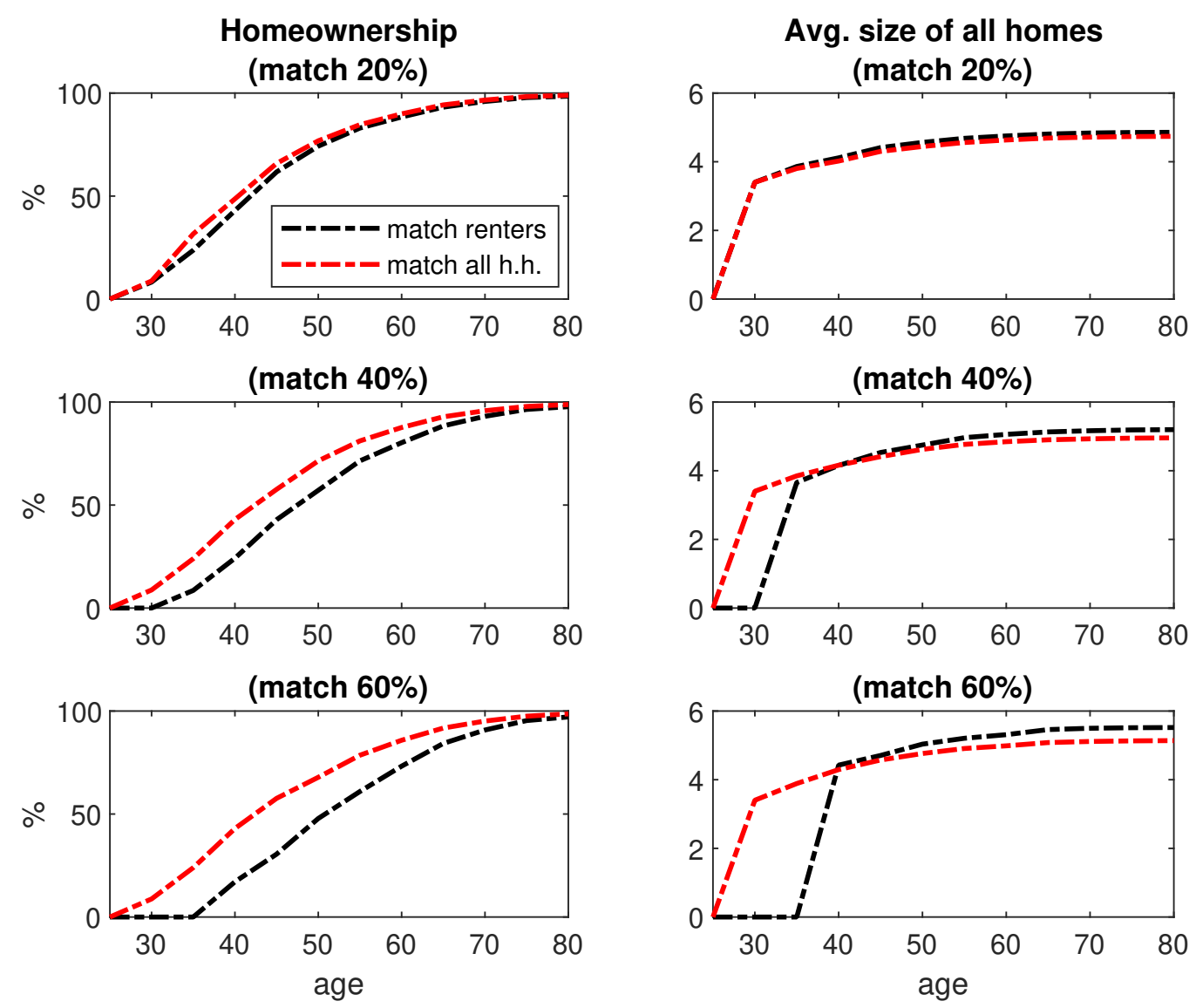

Notes: This figure illustrates homeownership and average home size under the program with employers matching non-homeowners' deposits and the program with employers matching deposits of all households. 
Figure 10: Rental housing size
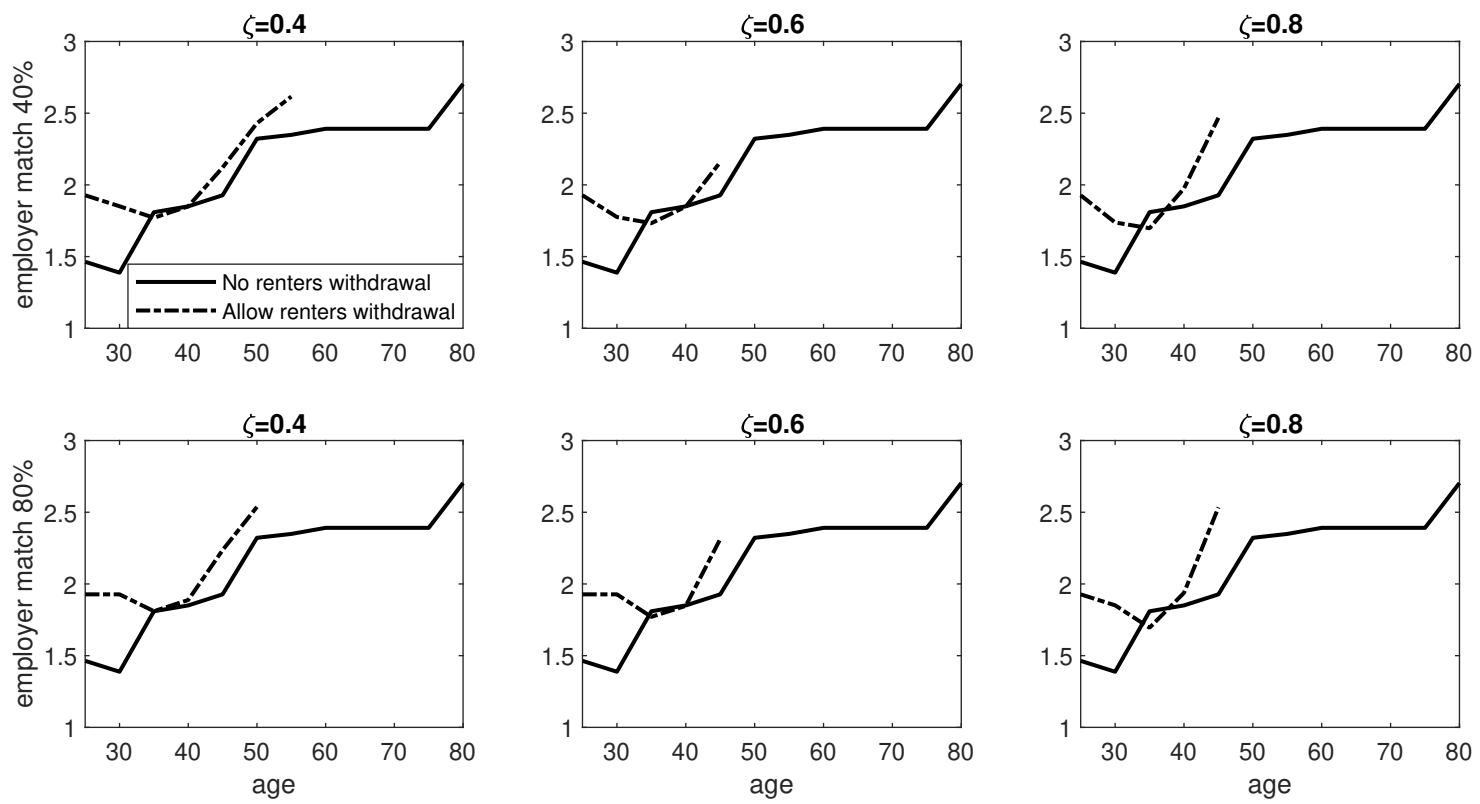

Notes: This figure illustrates the rental housing size when renters are not allowed to withdraw their HPF savings and when they are allowed to withdraw $\zeta$ of their total HPF savings.

Figure 11: Housing demand curves
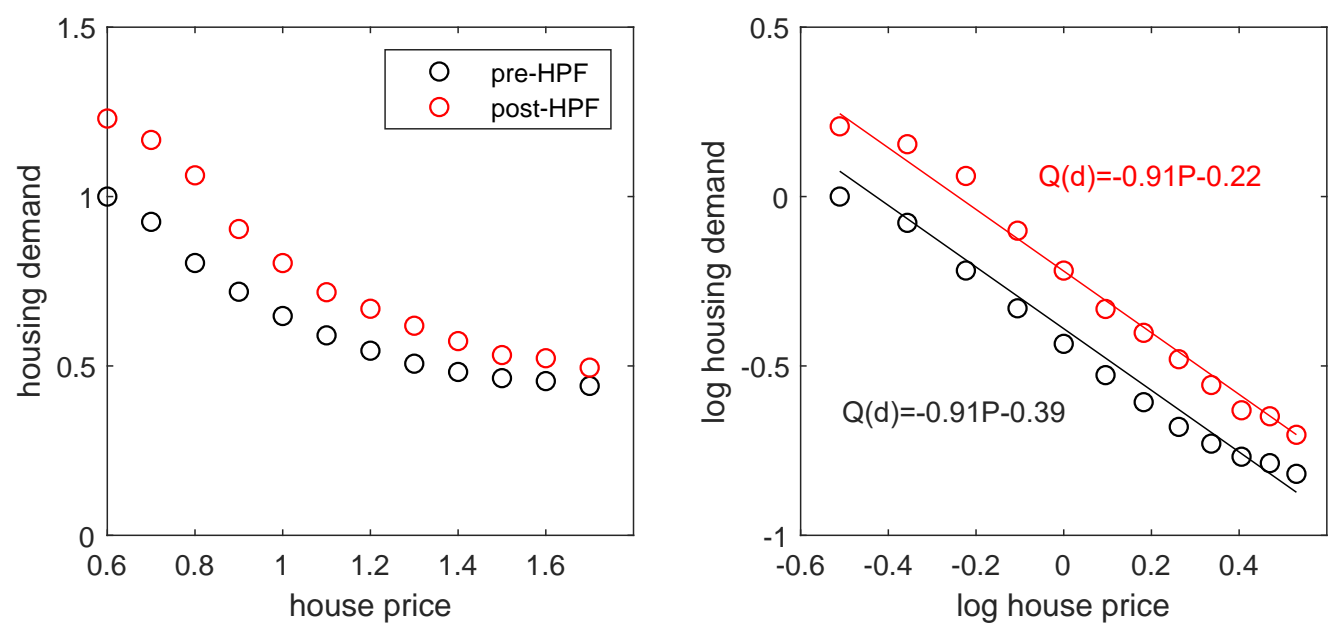

Notes: This figure illustrates the aggregate demand curves for housing before and after the HPF program is implemented. 
Table 1: Government-initiated saving programs intended to foster homeownership

\begin{tabular}{lcccl}
\hline \hline Country & Program & Mandatory & $\begin{array}{l}\text { Contribution } \\
\text { as a fraction } \\
\text { of income }(\%)\end{array}$ & Purpose \\
China & HPF & Yes & $5-20$ & Housing, retirement \\
Singapore & CPF & Yes & $5-20$ & $\begin{array}{l}\text { Housing, education } \\
\text { medical care, retirement }\end{array}$ \\
India & EPF & No & 12 & $\begin{array}{l}\text { Housing, education } \\
\text { medical care, retirement } \\
\text { marriage }\end{array}$ \\
Malaysia & EPF & Yes & $8-11$ & Housing, retirement \\
\hline \hline
\end{tabular}

Source: The official websites of these programs.

China's HPF (Ministry of Housing and Urban-Rural Development of China):

www.mohurd.gov.cn/zfgjjjg/index.html.

Singapore's CPF (CPF Board): www.cpf.gov.sg/members.

India's EPF (EPF Organisation): www.epfindia.com/site_en/.

Malaysia's EPF: www.kwsp.gov.my/portal/en/web/kwsp/home. 
Table 2: Baseline calibration

\begin{tabular}{|c|c|c|}
\hline Parameter & & Value \\
\hline \multicolumn{3}{|c|}{$\underline{\text { Demographics }}$} \\
\hline$J$ & Number of age groups & 12 \\
\hline$J_{y}$ & Number of working periods & 8 \\
\hline \multicolumn{3}{|l|}{$\underline{\text { Preferences }}$} \\
\hline$\beta$ & Discount factor & 0.93 \\
\hline$\xi$ & Utility weight on housing & 0.25 \\
\hline$\eta$ & Utility weight on bequest & 1 \\
\hline \multicolumn{3}{|l|}{ Income } \\
\hline$y_{1}$ & Income of age group 21-25 & 1 \\
\hline$b_{1}$ & Coef. of 1st age polynomial & 0.0232 \\
\hline$b_{2}$ & Coef. of 2 nd age polynomial & -0.000227 \\
\hline \multicolumn{3}{|c|}{ Housing and mortgage markets } \\
\hline $1-\gamma$ & Down-payment rate & 0.22 \\
\hline$\delta$ & Housing depreciation rate & 0 \\
\hline$f_{0}$ & Lower bound of transaction costs & 0 \\
\hline$f_{1}$ & Upper bound of transaction costs & 0.6 \\
\hline \multicolumn{3}{|c|}{$\underline{\text { Initial conditions }}$} \\
\hline$h_{0}$ & Owner-occupied home size & 0 \\
\hline$a_{0}$ & Liquid savings & 0 \\
\hline$b_{0}$ & Mortgage debt & 0 \\
\hline \multicolumn{3}{|l|}{$\underline{\text { Prices }}$} \\
\hline$p$ & House price & 1 \\
\hline$R / p$ & Rent-to-price ratio & 0.1 \\
\hline$r$ & Market interest rate & 0.05 \\
\hline \multicolumn{3}{|c|}{$\underline{\text { Policy parameters }}$} \\
\hline$\theta$ & Fraction of income deposited & 0.12 \\
\hline$r^{b}$ & Subsidized mortgage rate & 0.03 \\
\hline
\end{tabular}


Table 3: Summary of key results

\begin{tabular}{lcccc}
\hline \hline & Pre-policy & $\begin{array}{c}\text { HPF } \\
\text { program }\end{array}$ & $\begin{array}{c}\text { Mandatory savings } \\
\text { only }\end{array}$ & $\begin{array}{c}\text { Discounted mortgage } \\
\text { rate only }\end{array}$ \\
\hline Homeownership (\%) & 60.94 & 69.60 & 61.60 & 69.60 \\
Average home size & 3.20 & 3.85 & 3.22 & 3.85 \\
$\begin{array}{l}\text { Households never } \\
\text { owning a home (\%) }\end{array}$ & 4.39 & 1.24 & 3.54 & 1.24 \\
Expected utility & 0.76 & 1.09 & 0.76 & 1.09 \\
\hline \hline
\end{tabular}

Notes: Homeownership rate is the fraction of homeowners in the population. Average home size is the average size of all homes. Fraction of households who never own a home is the percent of households in a cohort who have not purchased a home in the last period of their life. Expected utility is discounted life-time expected utility. 
Table 4: Alternative policy scenarios

\begin{tabular}{|c|c|c|c|c|c|c|c|}
\hline & \multicolumn{7}{|c|}{ Homeownership (\%) } \\
\hline & $\Delta r=0$ & $\Delta r=0.005$ & $\Delta r=0.01$ & $\Delta r=0.015$ & $\Delta r=0.02$ & $\Delta r=0.025$ & $\Delta r=0.03$ \\
\hline$\theta=0$ & 60.94 & 64.63 & 65.79 & 65.98 & 69.60 & 70.16 & 70.62 \\
\hline$\theta=0.1$ & 60.94 & 62.38 & 65.79 & 65.98 & 69.60 & 70.16 & 70.62 \\
\hline$\theta=0.15$ & 62.40 & 62.88 & 66.04 & 66.22 & 69.81 & 70.16 & 71.24 \\
\hline$\theta=0.2$ & 71.07 & 71.07 & 71.32 & 70.74 & 70.97 & 70.97 & 71.54 \\
\hline \multirow{2}{*}{$\theta=0.25$} & 74.77 & 74.77 & 74.78 & 73.60 & 73.60 & 72.18 & 72.27 \\
\hline & \multicolumn{7}{|c|}{ Average home size } \\
\hline$\theta=0$ & 3.15 & 3.33 & 3.54 & 3.77 & 3.85 & 4.02 & 4.23 \\
\hline$\theta=0.1$ & 3.24 & 3.36 & 3.51 & 3.68 & 3.92 & 4.03 & 4.22 \\
\hline$\theta=0.15$ & 3.22 & 3.46 & 3.56 & 3.71 & 3.89 & 4.03 & 4.25 \\
\hline$\theta=0.2$ & 3.28 & 3.42 & 3.56 & 3.82 & 3.97 & 4.08 & 4.24 \\
\hline \multirow[t]{2}{*}{$\theta=0.25$} & 3.37 & 3.53 & 3.68 & 3.90 & 4.04 & 4.24 & 4.36 \\
\hline & \multicolumn{7}{|c|}{ Households never owning a home $(\%)$} \\
\hline$\theta=0$ & 4.39 & 3.18 & 2.09 & 1.77 & 1.24 & 0.80 & 0.55 \\
\hline$\theta=0.1$ & 4.39 & 3.53 & 2.09 & 1.77 & 1.24 & 0.80 & 0.55 \\
\hline$\theta=0.15$ & 3.20 & 2.32 & 1.66 & 1.40 & 0.99 & 0.70 & 0.43 \\
\hline$\theta=0.2$ & 0.87 & 0.87 & 0.54 & 0.54 & 0.43 & 0.43 & 0.37 \\
\hline \multirow[t]{2}{*}{$\theta=0.25$} & 0.22 & 0.22 & 0.16 & 0.15 & 0.13 & 0.17 & 0.14 \\
\hline & \multicolumn{7}{|c|}{$\underline{\text { Expected utility }}$} \\
\hline$\theta=0$ & 0.76 & 0.84 & 0.92 & 1.00 & 1.09 & 1.18 & 1.28 \\
\hline$\theta=0.1$ & 0.76 & 0.84 & 0.92 & 1.00 & 1.09 & 1.18 & 1.27 \\
\hline$\theta=0.15$ & 0.76 & 0.83 & 0.91 & 1.00 & 1.09 & 1.18 & 1.27 \\
\hline$\theta=0.2$ & 0.74 & 0.83 & 0.91 & 1.00 & 1.09 & 1.18 & 1.27 \\
\hline$\theta=0.25$ & 0.72 & 0.80 & 0.89 & 0.98 & 1.08 & 1.17 & 1.27 \\
\hline
\end{tabular}

Notes: See Table 3. 


\section{Not-for-Publication Appendix}

\section{A. Numerical Solution Method}

This appendix describes the two-step numerical procedure used to solve the models in the paper. I focus on how to solve the model in Section 2.3. The models in other sections can be solved similarly. The main idea is that in the first step, I solve value functions over a fixed-grid state space, and in the second step, given the realized path of state, I solve the optimal choices over a denser choice set.

To obtain the value function of existing homeowners in age group $j, V_{j}^{O}(a, h, b)$, I discretize the state space $(a, h, b)$. I choose 20 grids for $a$ and $h$, and 10 grids for $b$. Similarly, I discretize the state space $(a, f)$ to obtain the value function of non-homeowners in age group $j, V_{j}^{N O}(a, f)$. I choose 20 grids for $a$. For the random transaction cost, $f$, I discretize the continuous uniform distribution to a discrete uniform distribution. I choose 12 grids for $f$ over the support, and the probability for each realization is $1 / 12$.

I use the following algorithm to solve value functions in the first step. First, the terminal value is pinned down by the bequest function. Second, I construct a choice set for each given state. Specifically, in each period $j$ back to the initial period 0 , I compute two sets of value functions separately, one for existing homeowners, $V_{j}^{O}(a, h, b)$, and the other for households who have not bought a house at the beginning of the period, $V_{j}^{N O}(a, f)$. For existing homeowners, given $h$ and $b$, they choose $a^{\prime}$ optimally. I construct a choice set $\left\{a^{\prime}(a, h, b)\right\}$, which takes into account all constrains of the homeowner's problem. For households who have not bought a house at the beginning of the period with savings $a$, I compute the value of buying one, $V_{j}^{P}(a, f)$, given the realized transaction cost, $f$. The choice set is constructed over the space of $a$ and $f$ and takes into account all constraints for a new home buyer, expressed as $\left\{a^{\prime}(a, f), h^{\prime}(a, f), b^{\prime}(a, f), s(a, f)\right\}$. I also compute the value of not buying a house, $V_{j}^{N P}(a)$. The choice set $\left\{a^{\prime}(a), s(a)\right\}$ is constructed by taking into account the budget constraint and the liquidity constraint.

Third, I compute the corresponding value for each choice, and apply the linear interpolation technique if a choice is not on the grid points. For households who are not homeowners and choose not to buy a house in the current period, the continuation value is computed as the probability weighted average of the value of being non-homeowners in the next period with a transaction cost, $f^{\prime}$, i.e., $\mathbb{E}\left[V_{j+1}^{N O}\left(a^{\prime}, f^{\prime}\right)\right]=\int_{-\infty}^{\infty} V_{j+1}^{N O}\left(a^{\prime}, f^{\prime}\right) d F\left(f^{\prime}\right)$. Fourth, given a state, I compare the values 
obtained from all choices, and choose the maximum. This procedure yields $V_{j}^{O}(a, h, b), V_{j}^{P}(a, f)$, and $V_{j}^{N P}(a)$. The value of households who are not homeowners at the beginning of period $j$ is $V_{j}^{N O}(a, f)=\max \left\{V_{j}^{P}(a, f), V_{j}^{N P}(a)\right\}$, where $f$ is the transaction cost.

To obtain optimal choices in the second step, given a realized path of the previous state, I solve the optimization problem as described above by searching over a denser choice set. This allows me to improve the accuracy of the solution.

\section{B. Complementary Figures}

Figure B1: Evaluating the key HPF features separately
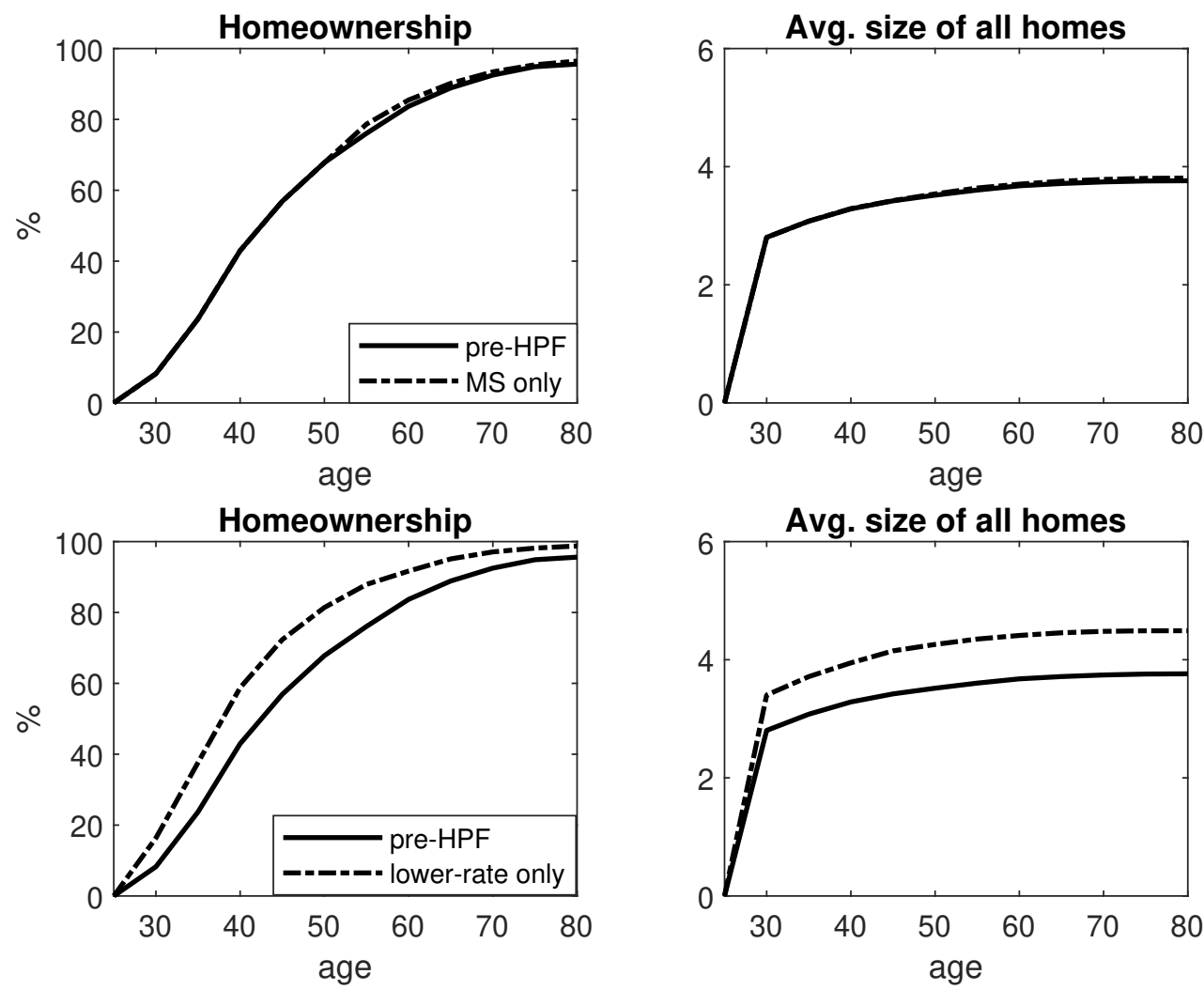

Notes: The upper panel shows the simulation results based on the mandatory saving only model in Section 2.2 with $\theta=0.12$. The lower panel shows the simulation results based on the discounted mortgage rate only model in Section 2.3 with $r-r^{b}=0.02$. 